\title{
Tubulin Beta-3 Chain as a New Candidate Protein Biomarker of Human Skin Aging: A Preliminary Study
}

\author{
Sylvia G. Lehmann, ${ }^{1}$ Sandrine Bourgoin-Voillard, ${ }^{2,3,4}$ Michel Seve, ${ }^{2,3,4}$ and Walid Rachidi ${ }^{5,6}$ \\ ${ }^{1}$ University Grenoble Alpes, ISTerre, CS 40700, 38058 Grenoble Cedex 9, France \\ ${ }^{2}$ University Grenoble Alpes, LBFA et BEeSy, PROMETHEE Proteomic Platform, Grenoble, France \\ ${ }^{3}$ Inserm, U1055, PROMETHEE Proteomic Platform, Grenoble, France \\ ${ }^{4}$ CHU Grenoble Alpes, Institut de Biologie et de Pathologie, PROMETHEE Proteomic Platform, Grenoble, France \\ ${ }^{5}$ University Grenoble Alpes, INAC, SyMMES, 38000 Grenoble, France \\ ${ }^{6}$ CEA, INAC, SyMMES, 38054 Grenoble, France
}

Correspondence should be addressed to Sylvia G. Lehmann; sylvia.lehmann@univ-grenoble-alpes.fr

Received 1 December 2016; Revised 1 March 2017; Accepted 19 March 2017; Published 23 May 2017

Academic Editor: Antonio Ayala

Copyright (c) 2017 Sylvia G. Lehmann et al. This is an open access article distributed under the Creative Commons Attribution License, which permits unrestricted use, distribution, and reproduction in any medium, provided the original work is properly cited.

\begin{abstract}
Skin aging is a complex process, and a lot of efforts have been made to identify new and specific targets that could help to diagnose, prevent, and treat skin aging. Several studies concerning skin aging have analyzed the changes in gene expression, and very few investigations have been performed at the protein level. Moreover, none of these proteomic studies has used a global quantitative labeled proteomic offgel approach that allows a more accurate description of aging phenotype. We applied such an approach on human primary keratinocytes obtained from sun-nonexposed skin biopsies of young and elderly women. A total of 517 unique proteins were identified, and 58 proteins were significantly differentially expressed with 40 that were downregulated and 18 upregulated with aging. Gene ontology and pathway analysis performed on these 58 putative biomarkers of skin aging evidenced that these dysregulated proteins were mostly involved in metabolism and cellular processes such as cell cycle and signaling pathways. Change of expression of tubulin beta-3 chain was confirmed by western blot on samples originated from several donors. Thus, this study suggested the tubulin beta-3 chain has a promising biomarker in skin aging.
\end{abstract}

\section{Introduction}

Life expectancy in developed countries over the past two centuries has considerably increased, and if this trend continues through the 21st century, most babies born since 2000 in such countries will reach 100 years. Also, it is expected that by 2030 , one in eight people worldwide will be 65 or above and the global aging of the population will lead to several societal, economical, and medical challenges [1].

Aging is a complex process influenced by multiple genetic and environmental factors and is characterized by a progressive decline in multiple physiological functions. Skin like other organs is affected by aging that can be accelerated by environmental factors such as UV radiation. Intrinsic skin aging is observed in sun-nonexposed skin and reflects the aging process of the entire organism [2]. Thereby, skin is an interesting alternative approach to decipher the intrinsic aging process as it is easily accessible compared to internal organs or tissues. Skin undergoes several morphological and physiological changes with intrinsic aging such as fine wrinkle formation, thinning of the epidermis and dermis, increased vulnerability and fragility, dryness, loss of elasticity, and disturbed barrier function [2]. The underlying mechanisms of intrinsic aging are multiple: cellular senescence and decreased proliferative capacity; shortening of the telomeres; increase in DNA damage and reduction in DNA repair processes; mitochondrial and genomic DNA mutations; hormonal decline and oxidative stress $[3,4]$.

Over the last decade, several transcriptomic studies have investigated the effect of aging on gene expression in several 
organism models and in humans $[5,6]$. Concerning skin aging, only few studies have been conducted in humans. The first showed that genes differently expressed in elderly and young human male skin were involved in various cellular processes such as metabolism, signal transduction, apoptosis, and regulation of transcription [7]. More recently, a study has compared the gene expression profile from sunnonexposed skin in both genders depending on aging. There was a significant different response in both genders with aging, with only 39 genes commonly dysregulated and 4 of them regulated in the opposite manner in both genders. From these results, the WNT signaling pathway has emerged as the major downregulated pathway with aging in both sexes [8]. And lately, 75 differentially expressed genes were identified in human epidermis according to age status [9]. Pathway analysis revealed that these genes were mainly involved in cell migration, cancer, dermatological diseases, and cell proliferation. Also, genes involved in the development of the epidermis were significantly enriched, and an overall downregulation of keratinocytes differentiation was observed.

Proteins are the workhorses of the cell and the main effectors of numerous cellular processes. Quantitative mass spectrometry-based proteomics has proven its utility for the description of protein dynamics in order to decipher complex processes and to describe normal and pathological states [10-13]. Relatively few studies have used proteomic to investigate skin aging, and they all used a two-dimensional gel electrophoresis approach which leads to a lower coverage of the proteome than gel-free approaches that could provide a proteomic signature of aging [14-16].

Skin is composed of several cell layers, and previous studies have investigated the protein expression level in whole skin or in stratum corneum samples. But the different cell layers can behave very differently and exhibit a different response to aging. Keratinocytes are the major components of the epidermis which is the most superficial and accessible layer of the skin. Focusing on keratinocytes will help to gain a deeper insight into skin aging and to have access to the proliferative compartment of the epidermis. Skin structure differs between genders, mainly due to the role of androgens in skin morphology. In humans, male skin is thicker than female skin and female subcutaneous tissues are thicker than male's one [17]. We then investigated the changes in the protein expression profile in human primary keratinocytes derived from sun-nonexposed skin obtained from young and elderly Caucasian women (mean age 62.5 years, $n=2$, and 29.5 years, $n=2$, resp.). Considering that the skin undergoes significant changes during menopause [18], the age categories were chosen so that the elderly women would have more probably reached menopause. Indeed, the average age where women reached menopause was $48.8 \pm 4$ years in a French cohort of women [19].

Our quantitative proteomic profiling, which expression was significantly dysregulated, of young and elderly primary human keratinocytes identified 58 proteins that are putative candidate biomarkers for intrinsic skin aging. Further western blot analysis on 14 donors confirms that tubulin beta-3 chain could be a biomarker of skin aging.

\section{Material and Methods}

2.1. Cell Culture. Human keratinocyte cultures were established by outgrowth from skin biopsies obtained after plastic mammary surgery (Centre Hospitalier Universitaire Grenoble Alpes, France) from healthy donors with their informed consent. Donors were Caucasian women aged 57-71 years $(n=10)$ and $18-32$ years $(n=8)$ classified in two age groups designed hereafter elderly and young, respectively. Skin biopsies were from sun-nonexposed skin. Isolation and culture of primary keratinocytes in KSFM medium supplemented with $25 \mu \mathrm{g} / \mathrm{mL}$ bovine pituitary extract (BPE), $1.5 \mathrm{ng} / \mathrm{mL}$ EGF (Life Technologies), and $75 \mu \mathrm{g} / \mathrm{mL}$ Primocin $^{\mathrm{TM}}$ (InvivoGen) were done as previously described [20]. To avoid replicative senescence, cells were used at passage 2 or 3 .

2.2. Protein Extraction for MS Analysis. Cultured keratinocytes obtained from young (27 and 32 years) and elderly (60 and 65 years) donors were cultivated up to passage 2 and harvested by trypsinization. After two washes with PBS (Life Technologies), cell pellets were kept at $-80^{\circ} \mathrm{C}$ up to the extraction. Frozen cell pellets were lysed for 30 minutes at $4^{\circ} \mathrm{C}$ in a solution containing $40 \mathrm{mM}$ HEPES $\mathrm{pH} 7.4$, $100 \mathrm{mM} \mathrm{NaCl}, 1 \mathrm{mM}$ EDTA, $0.02 \%$ Triton, $0.02 \%$ sodium deoxycholate, $0.2 \mathrm{mM}$ TCEP, and protease and phosphatase inhibitor cocktails (PhosSTOP) from Roche. Lysis was achieved by short sonication on ice, and the lysates were cleared by centrifugation at $14,000 \mathrm{rpm}$ for 20 minutes at $4^{\circ} \mathrm{C}$. The concentration of the protein extract was determined using BCA protein assay kit (Thermo Fisher Scientific, IL, USA).

2.3. Protein Digestion and TTRAQ Labeling. Protein samples were labeled with iTRAQ reagents according to the manufacturer's instructions (iTRAQ Reagents 8 plex Applications kit; Sciex, Framingham, MA, USA). Briefly, equal amount of protein extract obtained from cells originated from young donors was pooled in order to achieve a total of $100 \mu \mathrm{g}$ of proteins. The same procedure was applied for cells from elderly donors. The samples were reduced in $20 \mathrm{mM}$ of TCEP (tris(2-carboxyethyl)phosphine) at $37^{\circ} \mathrm{C}$ for $1 \mathrm{~h}$, and cysteine residues were blocked in $10 \mathrm{mM}$ of MMTS (methyl methanethiosulfonate) at room temperature for $10 \mathrm{~min}$, followed by trypsin (Promega, Lyon, France) digestion at a ratio of $1: 10$ (trypsin : protein) at $37^{\circ} \mathrm{C}$ overnight. Each peptide solution was labeled with one iTRAQ reagent: iTRAQ reporter ions of $\mathrm{m} / z 113.1$ for young and $\mathrm{m} / z 117.1$ for elderly. iTRAQ labeling was verified for all reactions, and the samples were pooled in a ratio $1: 1$ and dried by vacuum centrifugation prior to the OFFGEL peptide fractionation.

2.4. Peptide OFFGEL Isoelectrofocusing. Peptide fractionation according to their pI was performed with 3100 OFFGEL Fractionator and the OFFGEL Kit linear pH 3-10 (Agilent Technology, Les Ulis, France) in a 24-well setup following the manufacturer's instructions. The device was set up for the 24-fraction separation by using a $24-\mathrm{cm}-$ long IPG gel strip with a linear $\mathrm{pH}$ gradient ranging at 3-10. iTRAQlabeled peptide mix was dried by vacuum centrifugation and resuspended in focusing OFFGEL buffer prior to loading 
in each of the 24 wells. Peptides were focused with a constant current of $50 \mu \mathrm{A}$ until $50 \mathrm{kVh}$ was reached. After complete fractionation, peptide samples were recovered from each well, dried in a vacuum concentrator, and then desalted using C18 ZipTips (Millipore, MA, USA).

2.5. Reversed Phase Nanoliquid Chromatography. Further peptide separation was performed on an Ultimate 3000 C18 reversed phase nanoliquid chromatography (RP-nanoLC) system (Ultimate 3000, Dionex/Thermo Scientific) controlled by Chromeleon v. 6.80 software (Dionex/Thermo Scientific/LC Packings, Amsterdam, The Netherlands) and coupled with a PROBOT MALDI spotting device controlled by the $\mu$ Carrier 2.0 software (Dionex/Thermo Scientific/LC Packings, Amsterdam, The Netherlands). Vacuum dried fractions were resuspended in buffer A (98\% water, 2\% $\mathrm{ACN}$, and $0.05 \%$ TFA) before injection on a nanotrapping column $(\mathrm{C} 18,3 \mu \mathrm{m}, 100 \AA$ pore size; LC Packing) in $2 \%$ ACN and $0.05 \%$ TFA at a flow rate of $20 \mu \mathrm{L} / \mathrm{min}$ for $5 \mathrm{~min}$. Then, trapped peptides were separated by reversed phase chromatography (Acclaim PepMap300 $75 \mu \mathrm{m}, 15 \mathrm{~cm}$, nanoViper C18, $3 \mu \mathrm{m}, 100 \AA$ pore size; Thermo Scientific) with a binary gradient of buffer A ( $2 \% \mathrm{ACN}$ and $0.05 \% \mathrm{TFA})$ and buffer $\mathrm{B}(80 \% \mathrm{ACN}$ and $0.04 \% \mathrm{TFA})$ at a flow rate of $0.3 \mu \mathrm{L} / \mathrm{min}$. The entire run lasted $60 \mathrm{~min}$, and the nanoLC gradient was set up as follows: $5-35 \mathrm{~min}, 8-42 \% \mathrm{~B}$; 35$40 \mathrm{~min}, 42-58 \% \mathrm{~B} ; 40-50 \mathrm{~min}, 58-90 \% \mathrm{~B}$; and $50-60 \mathrm{~min}$, $90 \%$ B. Fractions from eluted solution were collected and spotted on a MALDI sample plate (Sciex, Les Ulis, France) at a frequency of one spot per 15 seconds. The $\alpha$-cyano-4hydroxy-cinnamic acid matrix (HCCA, $2 \mathrm{mg} / \mathrm{mL}$ in $70 \%$ ACN and $0.1 \%$ TFA) was continuously added to the column effluent at a flow rate of $0.9 \mu \mathrm{L} / \mathrm{min}$ and, therefore, integrated in each spot of MALDI sample plate.

2.6. MALDI-TOF/TOF Analysis. MS and MS/MS analysis of nanoLC-off-line spotted peptide samples was performed using the 4800 MALDI-TOF/TOF mass spectrometer (Sciex, Les Ulis, France) controlled by the 4000 Series Explorer software v. 3.5. The mass spectrometer was operated in a positive reflector mode. Each spectrum was externally calibrated using the Peptide Calibration Standard II (Bruker Daltonics, Bremen, Germany), and the peptide mass tolerance was set to 50 ppm. MS spectra were acquired in a $m / z 700-4000$ range. Up to 30 of the most intense ions per spot position characterized by a $S / N$ (signal/noise) ratio higher than 40 were chosen for MS/MS analysis. Selected ions were activated by using CID (collision-induced dissociation) in order to obtain the corresponding MS/MS spectrum.

2.7. Analysis of iTRAQ Data. MS and MS/MS spectra were used for identification and relative quantitation by using ProteinPilot $^{\mathrm{TM}}$ software v 4.0 with the Paragon ${ }^{\mathrm{TM}}$ (Sciex, Les Ulis, France) and Mascot (Matrix Science, London, UK) search engines. The analysis was performed with the UniProtKB database released on June 2015, and the taxonomy was limited to Homo sapiens. Concerning Paragon search engine, the search effort was set to "Thorough ID" and the False Discovery Rate Analysis (FDR) of 1\% was applied.
For quantification, bias and background correction was applied and only quantified proteins with at least 1 peptide at the $95 \%$ peptide confidence level were included. For Mascot search engine, the FDR was set lower than $1 \%$ and only peptides with a score higher than 30 were considered. Data were merged at the peptide level after Paragon and Mascot analysis. In order to obtain a high-quality quantitative analysis, we analyzed our data with the $\mathrm{R}$ package Isobar [21] which allows the determination of statistical significance of protein/peptide regulation. A normal fit was used and only proteins which ratio had a $p$ value ratio and a $p$ value sample $<0.05$ are then considered as significantly differently expressed depending on age. For output of our quantitative iTRAQ results, all protein ratios were expressed as elderly over young $(117: 113)$ to present relative protein quantification ratios. A summary of the parameters applied for the mass data analysis is presented in Supplemental Data (Table S1) available online at https://doi.org/10.1155/2017/5140360.

2.8. Gene Ontology and Pathway Analysis. Gene ontology and protein function analysis were performed using PANTHER (http://www.pantherdb.org/) [22] by importing the list of dysregulated proteins. Each protein was classified into one or several categories regarding PANTHER family, protein class, GO-slim molecular function, biological process, cellular component, and pathway. This functional classification of proteins regarding biological process and protein class is graphically illustrated in a pie chart. Pathway enrichment analysis was performed with PathVisio 3.2.2 Revision: 4047 [23] by importing the list presented in Table S2. The following criteria have been used $[\log 10$ ratio] $<-0.15$ OR $[\log 10$ ratio] $>0.16 \mathrm{AND}$ [is significant $]=1$ and the calculation method was pathwaycentric. The top enriched pathways and their $Z$-scores are represented.

2.9. Western Blot Analysis. Human primary keratinocytes were harvested and cultivated as described previously from skin biopsies of 8 young (age: 18, 21, 24, 26, 27 (2 donors), 30 , and 32) and 10 elderly donors (age: 57, 59, 60, 62 (2), 65 (2), 66, 68, and 71). At early passages ( 2 or 3 , when cells are still proliferating), cells were lysed by vortexing in RIPA Buffer (Sigma-Aldrich) containing protease inhibitors (Complete Mini protease inhibitor cocktail, Roche, Switzerland), $1 \mathrm{mM}$ DTT and $100 \mu \mathrm{M}$ PMSF. Samples were then centrifuged for 15 minutes at 14,000 rpm and the supernatants collected. Protein concentration was determined with MicroBC Assay (Interchim), and $20 \mu \mathrm{g}$ of total protein was loaded on TGX Stain-Free ${ }^{\mathrm{TM}}$ FastCast $^{\mathrm{TM}}$ 12\% Acrylamide gels (Biorad). Proteins were transferred onto a nitrocellulose membrane using Trans-Blot ${ }^{\circledR}$ Turbo $^{\mathrm{TM}}$ Transfert System (Biorad). Membranes were blocked with TBS-Tween $0.5 \%$ containing $5 \%$ nonfat milk and incubated with the tubulin beta- 3 chain antibody (MA1-118; Thermoscientific) at 1/1000 dilution in TBS-Tween $0.5 \%$ containing $5 \%$ nonfat milk overnight at $4^{\circ} \mathrm{C}$. After washing in TBS-Tween $0.5 \%$, membranes were incubated with HRP conjugated secondary antibodies (Amersham ECL anti-mouse IgG HRP-linked, whole antibody, GE Healthcare) for $1 \mathrm{~h}$ at RT. Membranes were then 
washed in TBS-Tween $0.5 \%$, and blot images were acquired on Molecular Imager Gel Doc XR+ and Chemidoc XRS+ Systems (Biorad). Specific detected bands were quantified with Image LAb 2.0 Software (Biorad), and corresponding intensities were normalized with total protein content and expressed as a ratio.

Western blot results of tubulin beta- 3 chain were illustrated by box plots, and receiver operating characteristic curve (ROC curve) was created by using GraphPad Prism version 7.00 for Windows (GraphPad Software, La Jolla California USA, http://www.graphpad.com).

\section{Results}

3.1. Identification of Fifty-Eight Proteins Differentially Expressed with Aging by Proteomic Analysis. In order to obtain a quantitative proteomic map of elderly and young donor-derived keratinocyte cells, we used an iTRAQ labeling coupled with OFFGEL fractionation and off-line nanoLC/ MS/MS as previously described [24]. The bioinformatics analysis with Paragon and Mascot search engines resulted in the identification of 517 unique proteins using a 1\% FDR and considering only proteins with at least 1 peptide with confidence level $\geq 95 \%$ and score $>30$. We performed a statistical analysis with the isobar package and quantified 446 proteins. Elderly keratinocytes were labeled with iTRAQ $\mathrm{m} / \mathrm{z}$ 117 tag and young keratinocytes with iTRAQ $\mathrm{m} / \mathrm{z} 113 \mathrm{tag}$. Thus, the ratio 117:113 (Elderly: Young) indicates the relative protein abundance between elderly and young cell samples. The complete list of identified proteins, including the UniProtKB accession number, ID, protein and gene name, peptide count, spectral count, sequence coverage, iTRAQ ratios with corresponding $p$ value ratio and $p$ value sample for elderly versus young cells are provided in Supplemental Data (Table S2). When the $p$ value ratio and the $p$ value sample were both $<0.05$, proteins were considered significantly differently expressed. Applying these criteria, we identified 58 proteins significantly differentially expressed depending on age status. From them, 40 were downregulated and 18 were upregulated with aging (Tables 1 and 2).

3.2. Gene Ontology Analysis. The 58 proteins previously identified were analyzed using PANTHER [22]. Their classifications into gene ontology and PANTHER categories are as follows: protein family, protein class, molecular function, biological process, cellular component, and pathway is listed in Table 3. This functional classification of biological process and PANTHER protein class is graphically illustrated in Figure 1. The main represented biological process categories are metabolism (30\%); cellular process including cell cycle/cell signaling pathways/cell component movement (21\%); cellular component organization/biological regulation (10\%); localization/developmental process (8\%); response to stimuli (4\%); multicellular organismal process/immune system process (3\%); and biological adhesion (1\%). Concerning protein class, dysregulated proteins belong to the main following protein classes: nucleic acid binding (25\%); cytoskeletal protein (13\%); enzyme modulator (12\%); oxidoreductase and signaling molecules (8\%); chaperone (6\%); transferase/transcription factor (4\%); and extracellular matrix protein/hydrolase/carrier protein/membrane traffic protein/cell junction protein/kinase/isomerase/ receptor (2\%).

Pathway enrichment analysis was performed using PathVisio [23], and the top enriched pathways are listed in Table 4. Metal homeostasis is in the top enriched pathways, as well as histone modifications, DNA replication, oxidative stress, and electron transport chain pathways.

3.3. Western Blot Analysis of Tubulin Beta-3 Chain, a Promising Candidate Protein Biomarker of Aging. In proteomic quantitation analysis, tubulin beta-3 chain was evidenced as a promising candidate protein biomarker of aging. Indeed, tubulin beta-3 chain was upregulated in elderly donors with an iTRAQ ratio of protein expression level of 2.66 (elderly versus young) and significant $p$ values ( $p$ value ratio of $4.21 \times 10^{-4}$ and a $p$ value sample of $\left.4.87 \times 10^{-7}\right)$. Thus, tubulin beta- 3 chain was further analyzed by western blot on human primary keratinocyte cells from the same donors but also from at least fourteen other donors in order to exclude the interindividual variability and to figure out whether or not these proteins were dysregulated in other donors. For this western blot analysis, total protein quantification was used as a control of gel loading and relative intensity of the specific antibodies on the membrane versus the amount of protein loaded on the gel was calculated and represented on box-plot diagram. Representative western blot images and results of quantification are shown in Figure 2. The trend of dysregulation of tubulin beta-3 chain was confirmed, and a similar ratio was obtained by western blot quantification and with our proteomic workflow. Moreover, receiver operating characteristic curve (ROC curve) confirmed the specificity and the sensitivity of tubulin beta3 chain expression level for determination of age status with an area under the ROC curve of 0.9048 and a $p$ value of 0.0152 .

\section{Discussion}

Skin aging is a complex process with multifactorial origins that can decipher using new technological approach such as global quantitative proteomics. We carried out an iTRAQMALDI-TOF/TOF MS and MS/MS analysis to identify and quantify changes in human primary keratinocyte proteomes from young and elderly donors. 517 proteins were identified including proteins found mainly in keratinocytes such as cornifin-B and keratin-2E which are associated with keratinocyte activation, proliferation, and keratinization [25]. After applying robust statistical analysis, 58 proteins were found significantly differentially expressed depending on age status with 40 that were downregulated and 18 upregulated with aging.

Comparison of our results with previous gene and protein expression studies of skin aging shows some similarities. We found that more proteins are downregulated (40) than upregulated (18) with aging which is consistent with the previous results from a gene expression study in women [8]. The majority of proteins which expression is affected by age are 


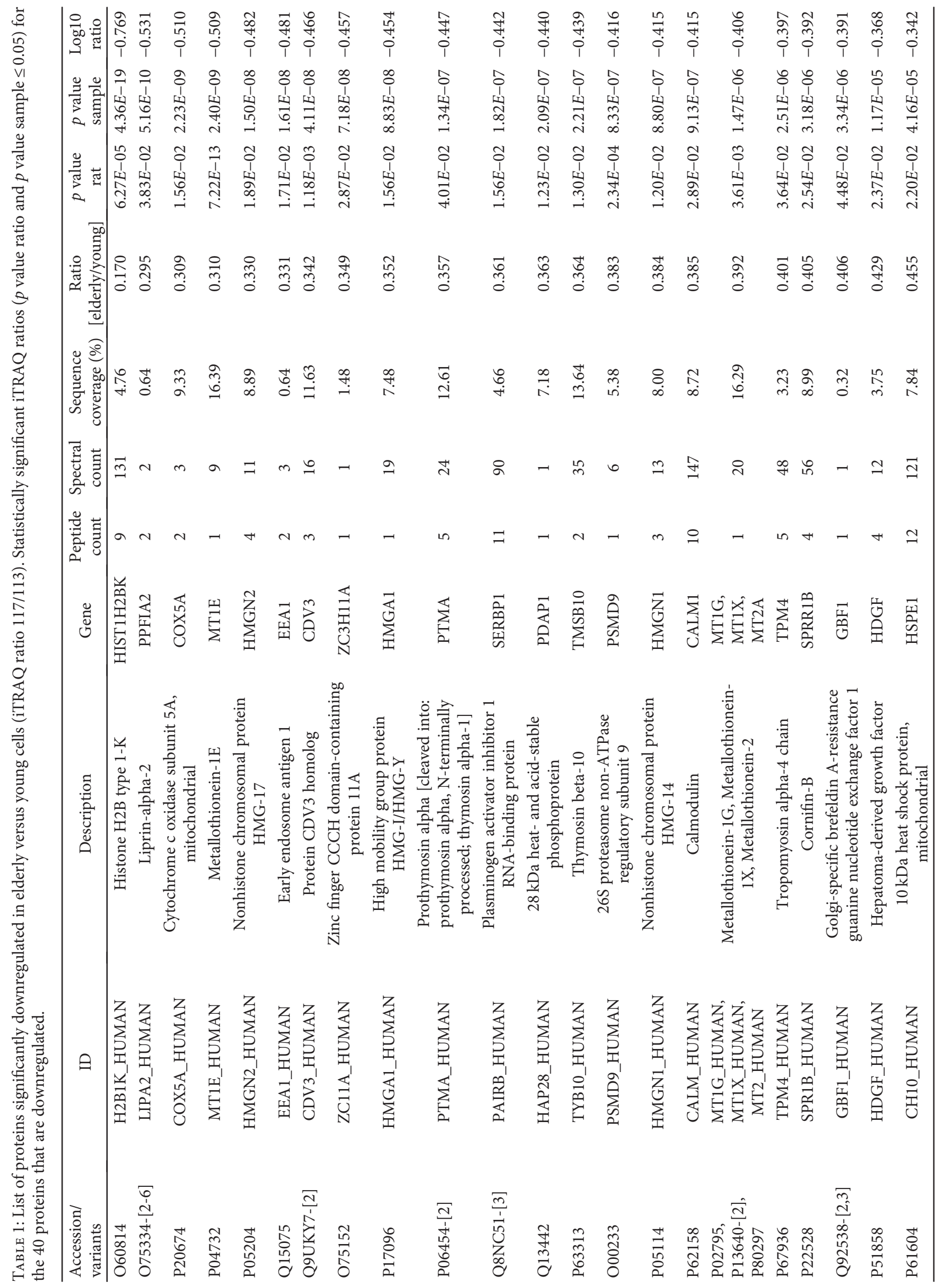




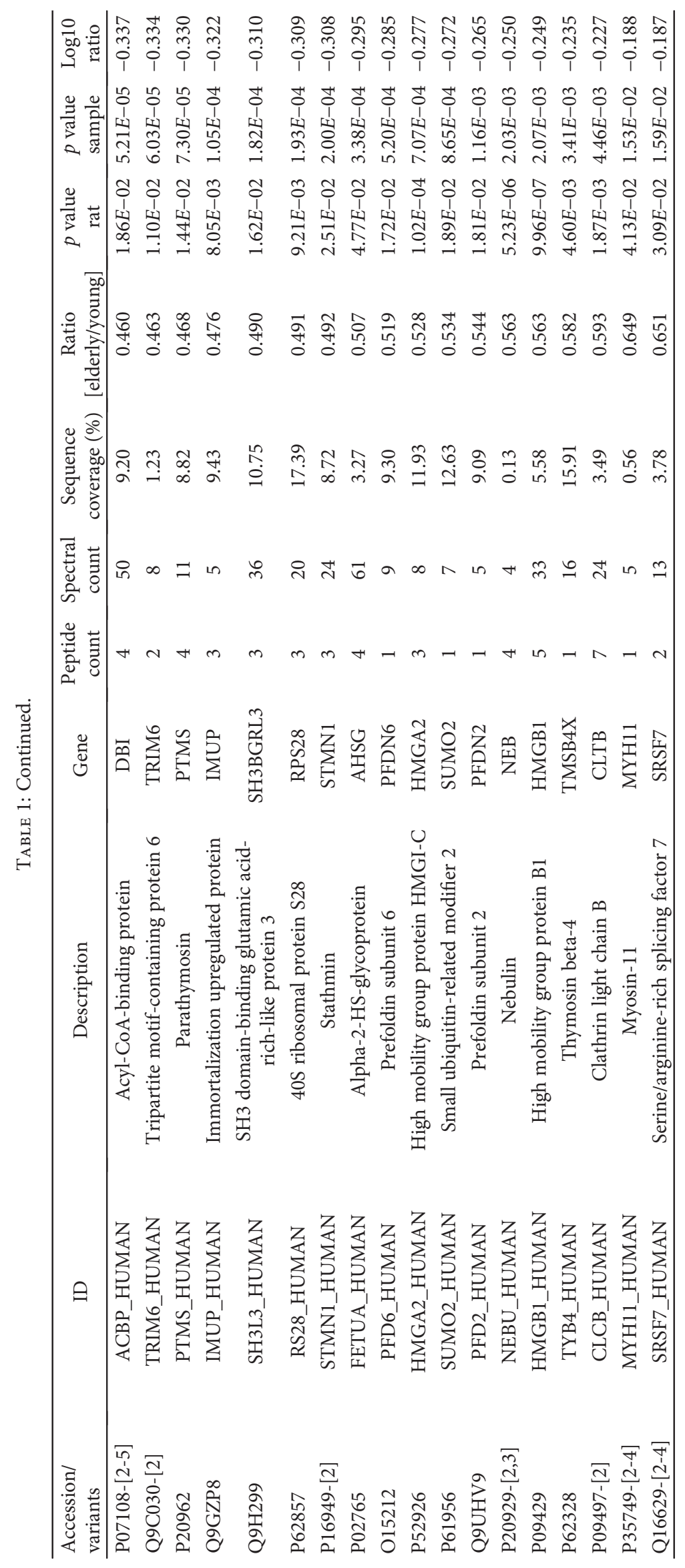




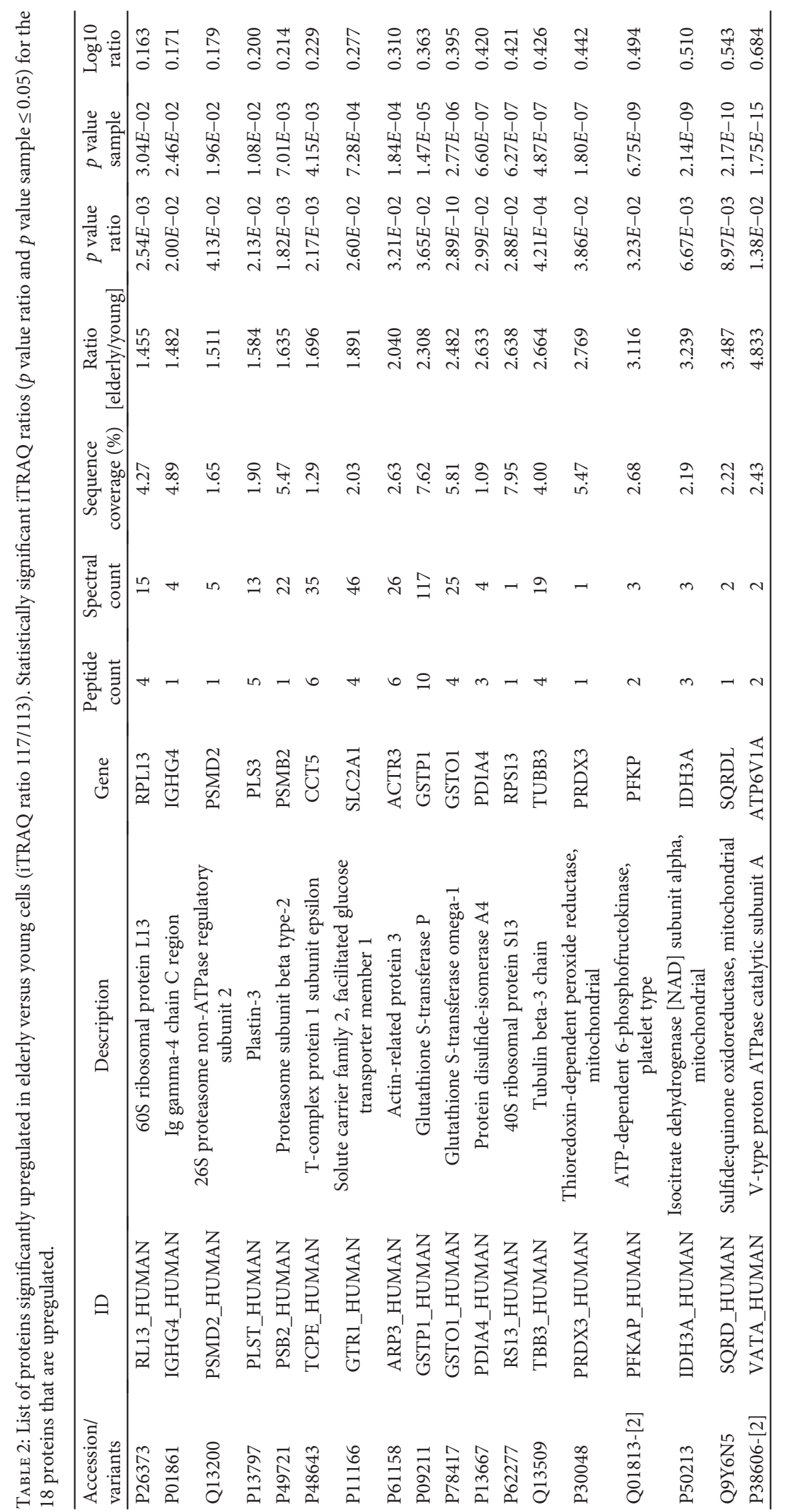




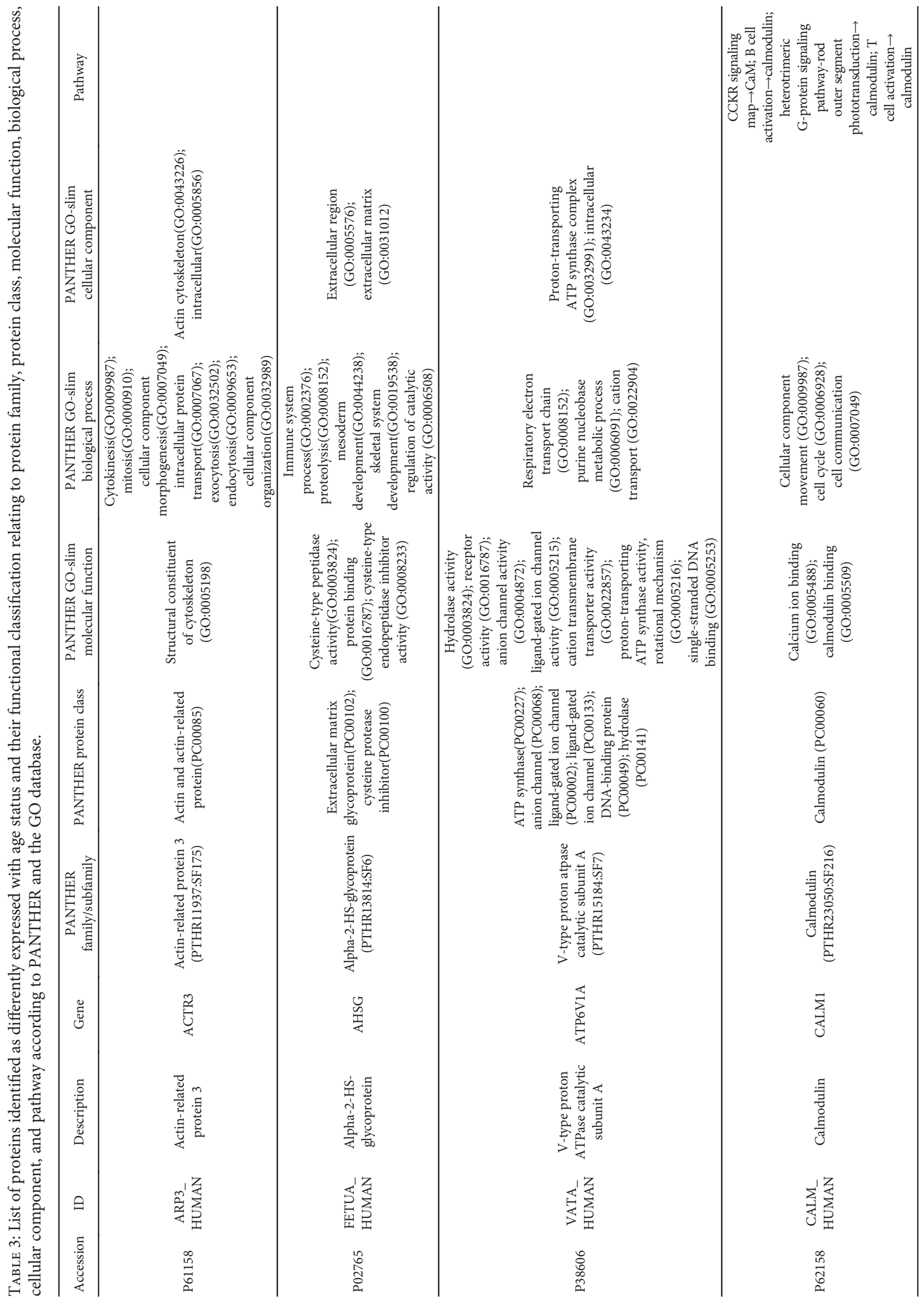




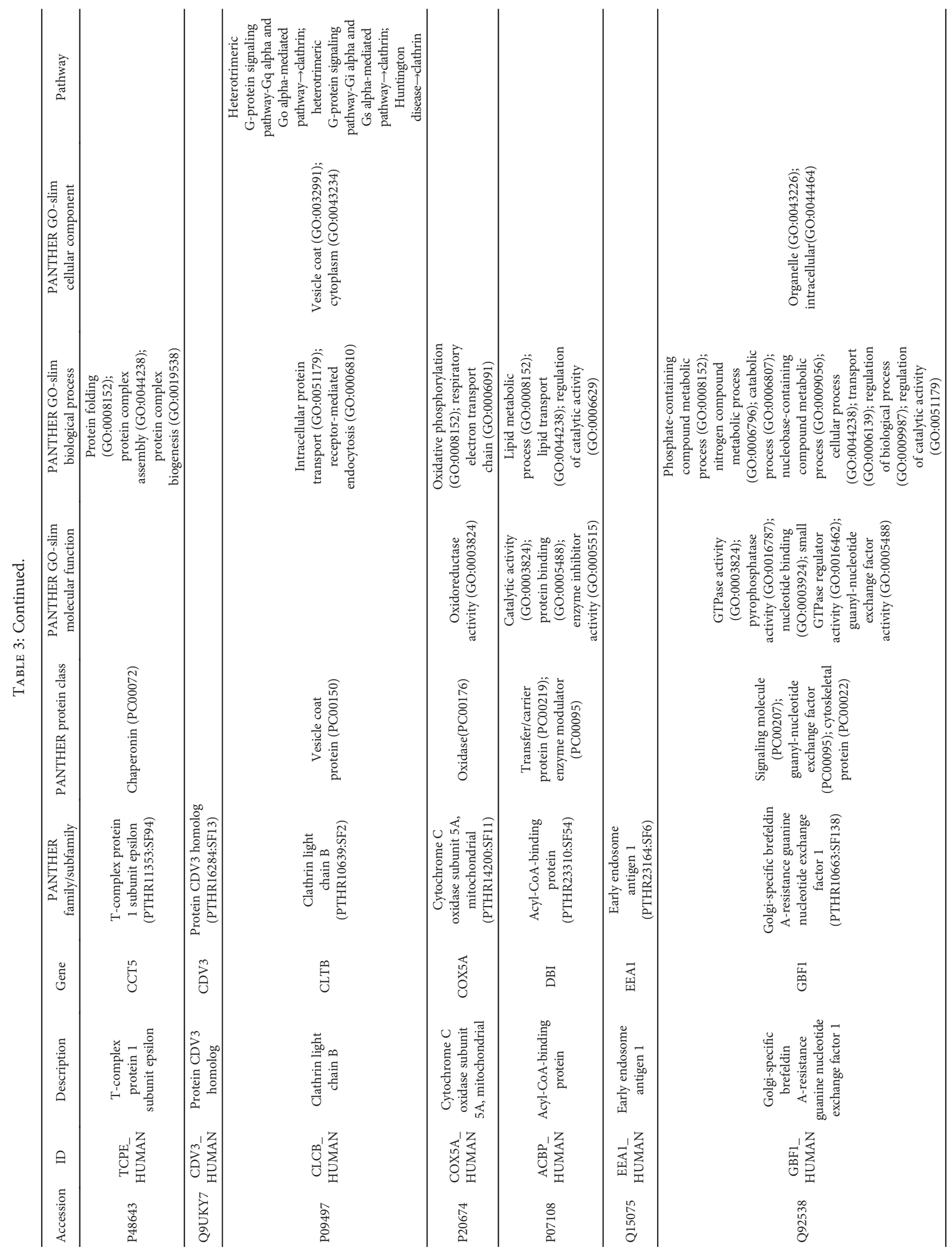




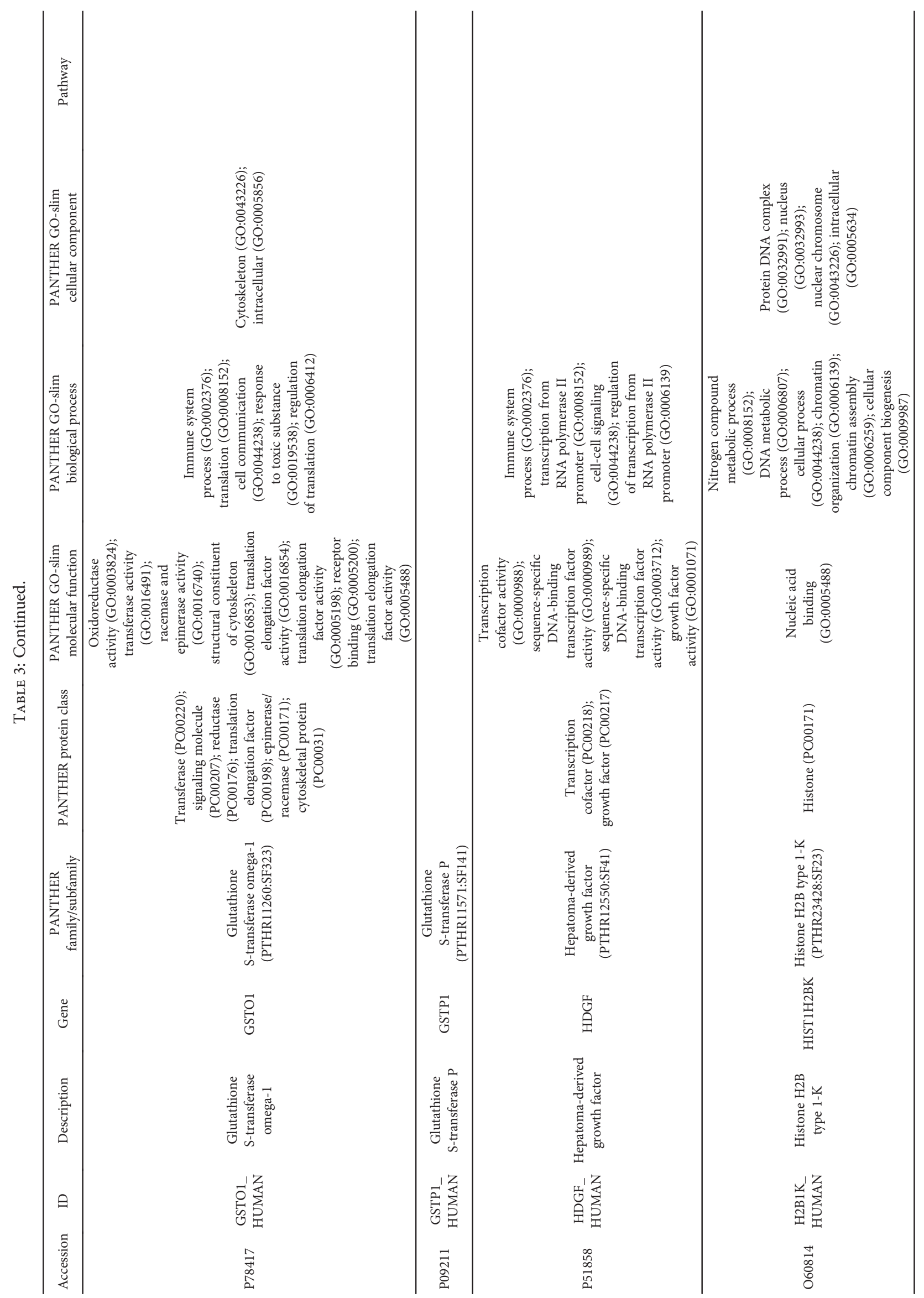




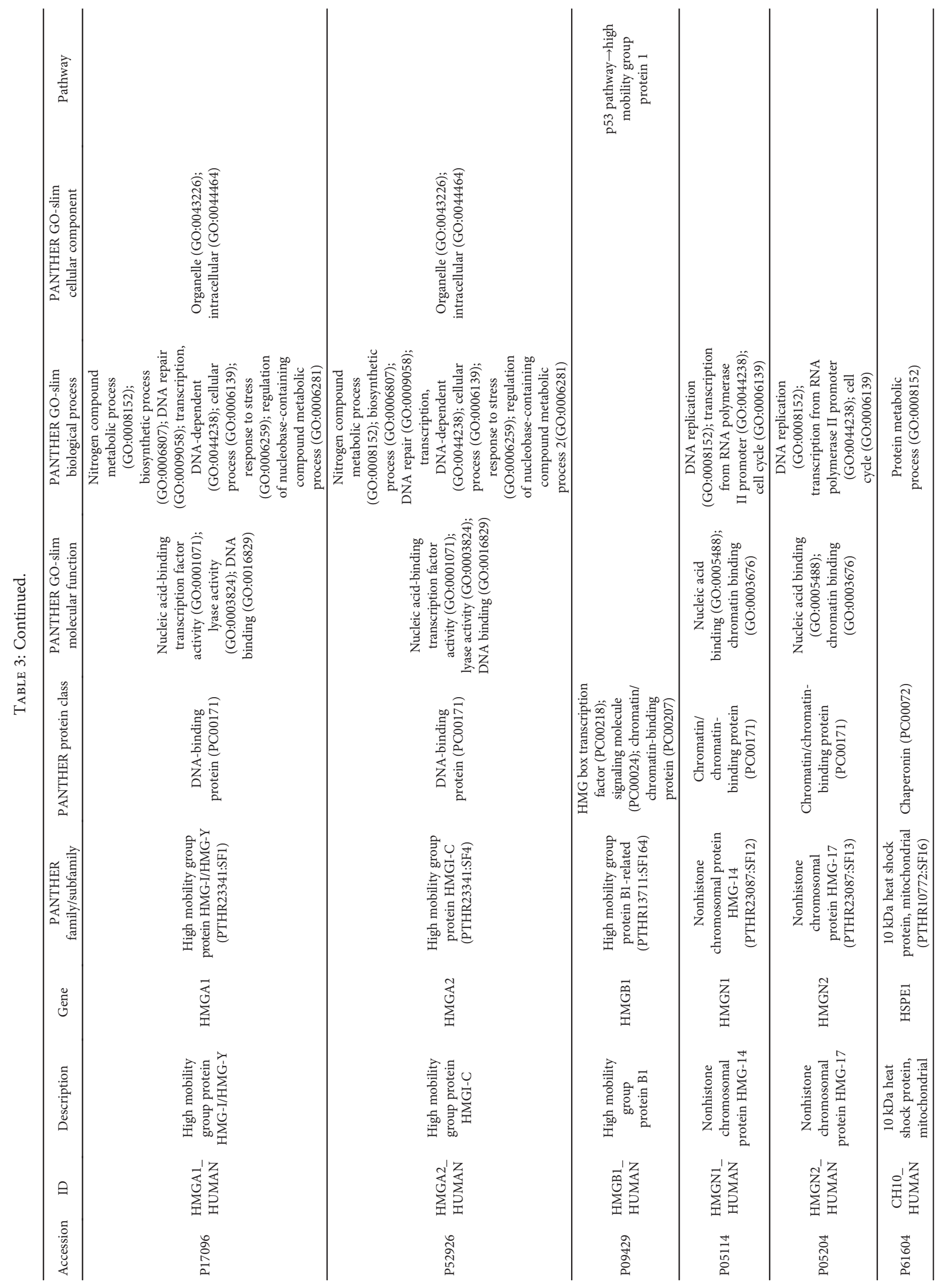




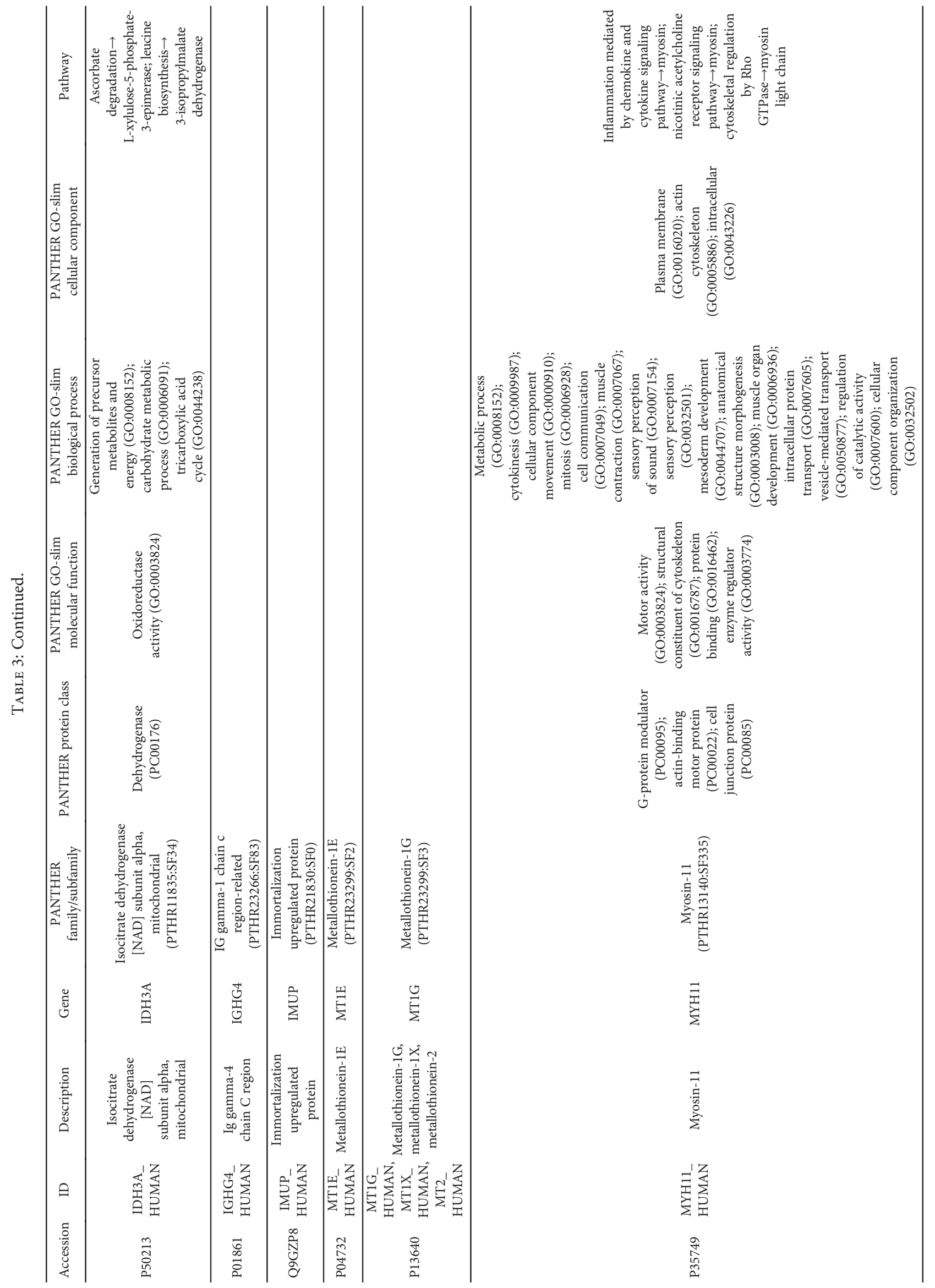




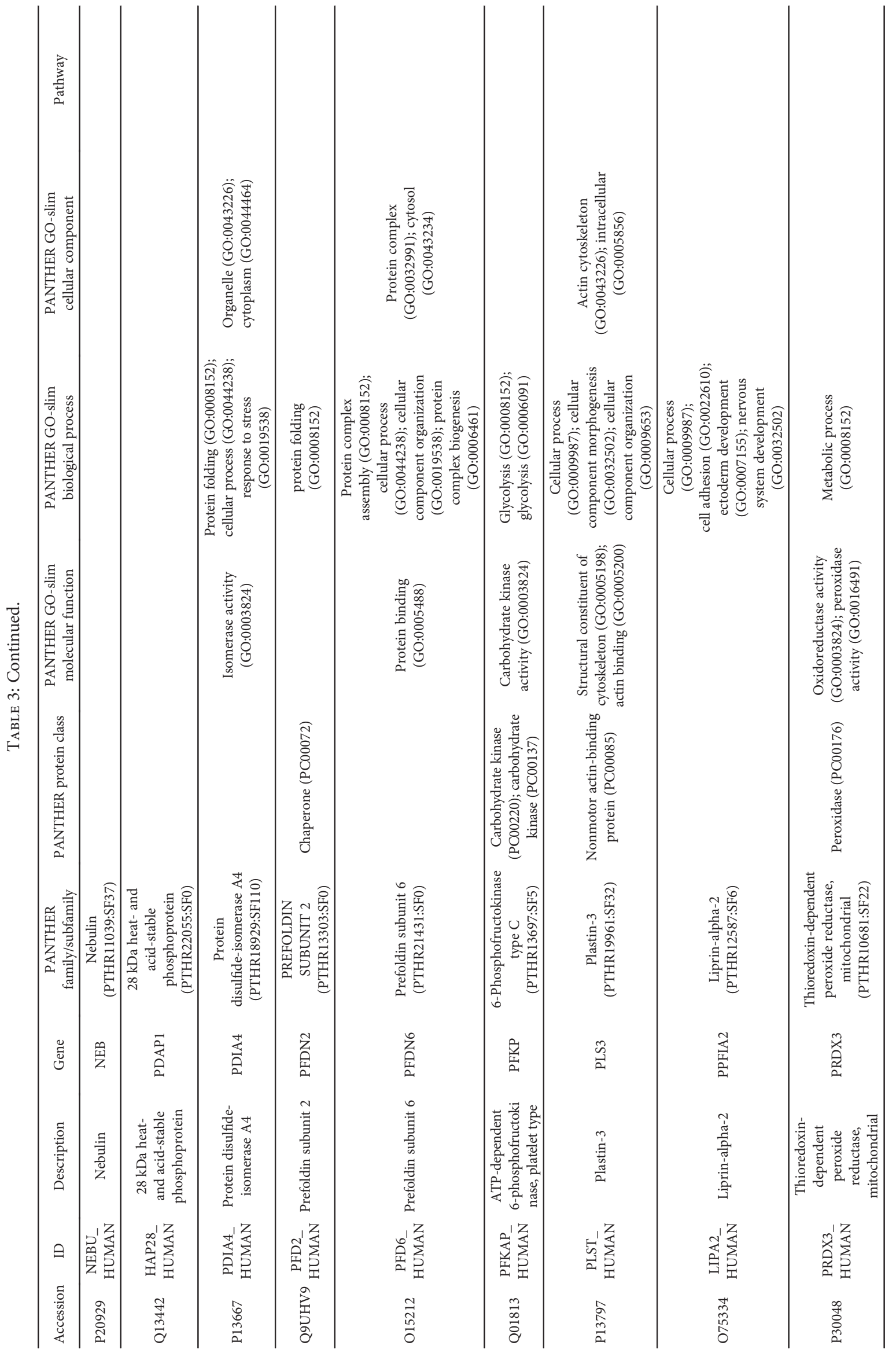




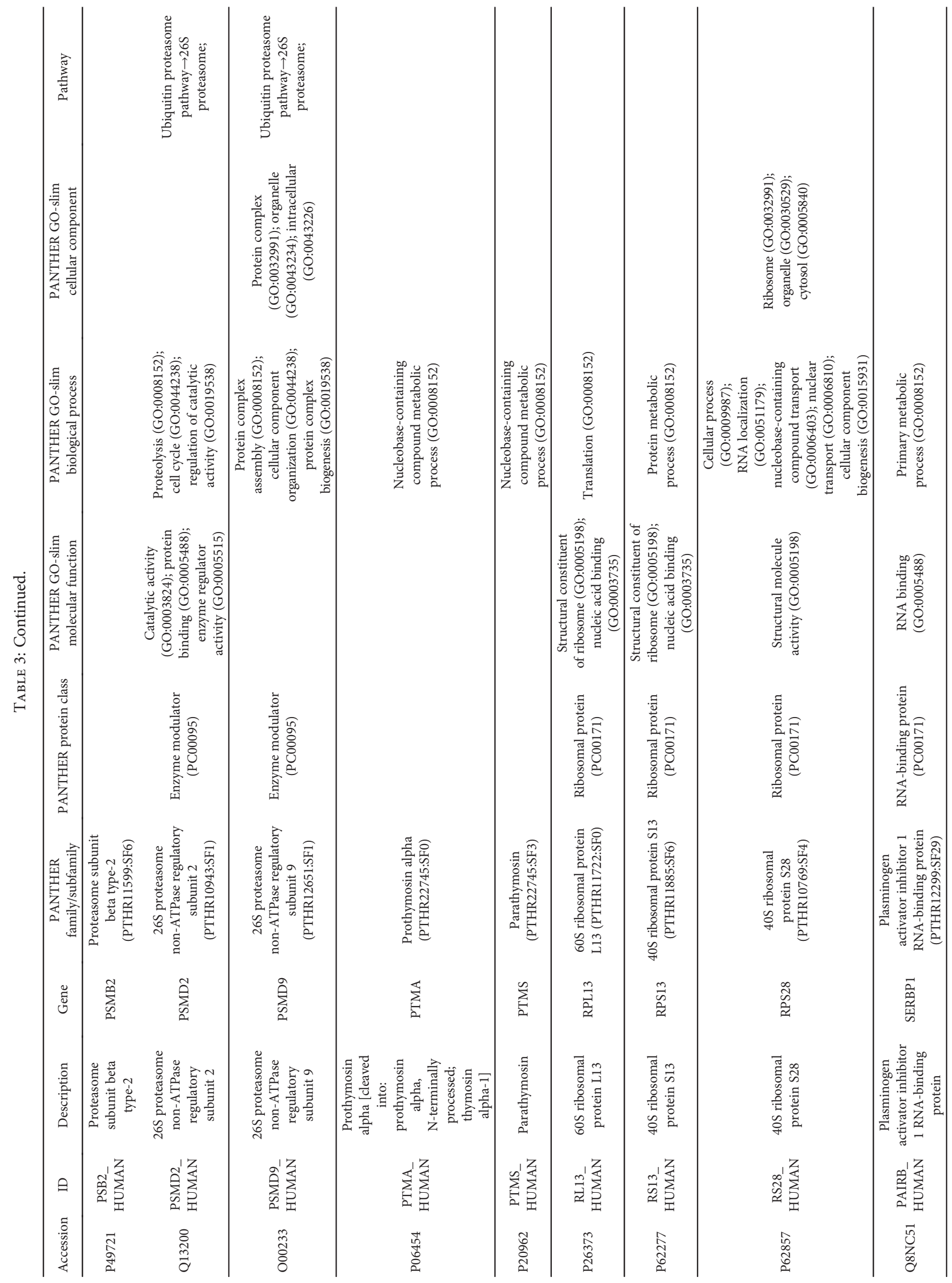




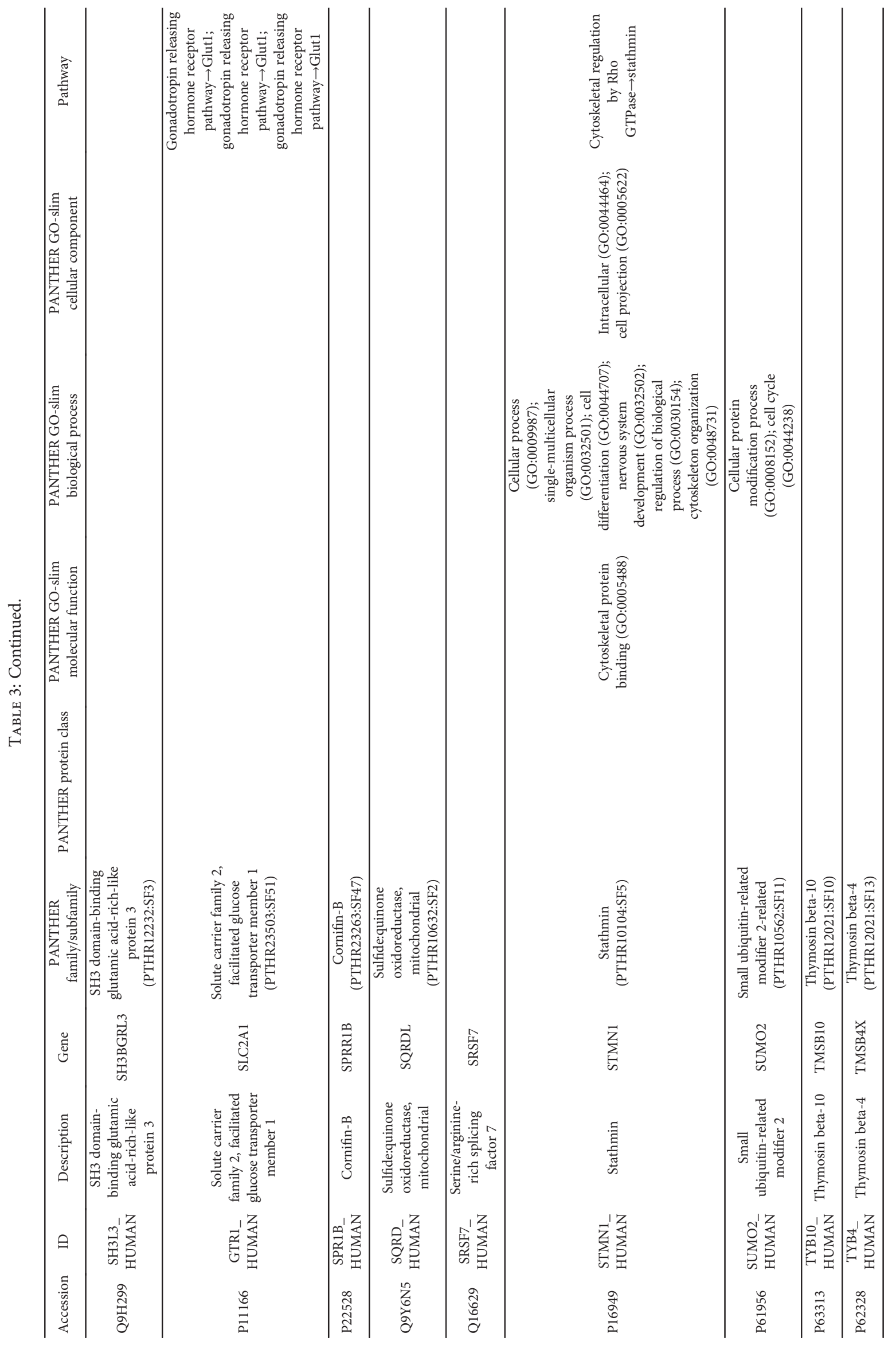




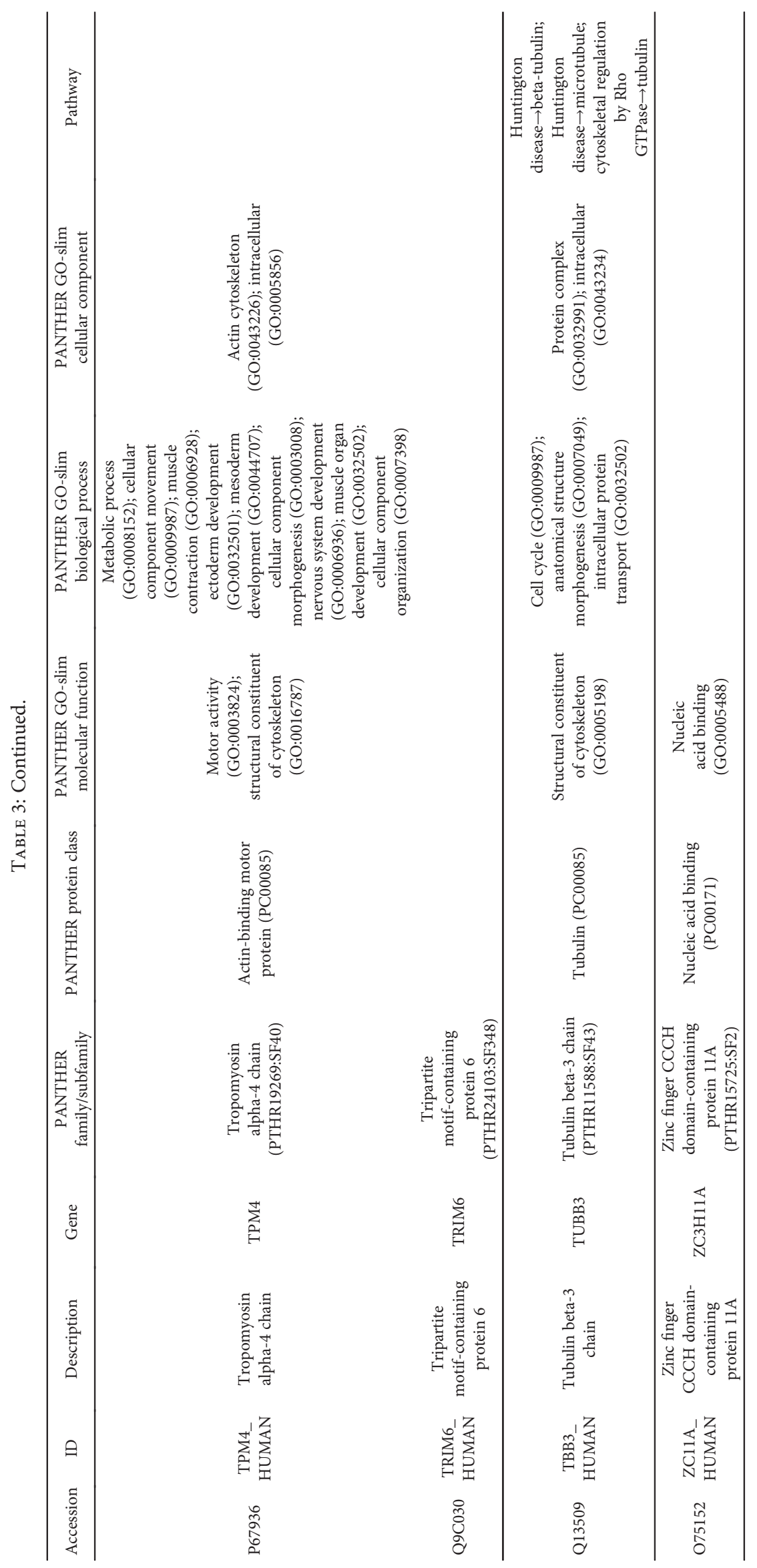




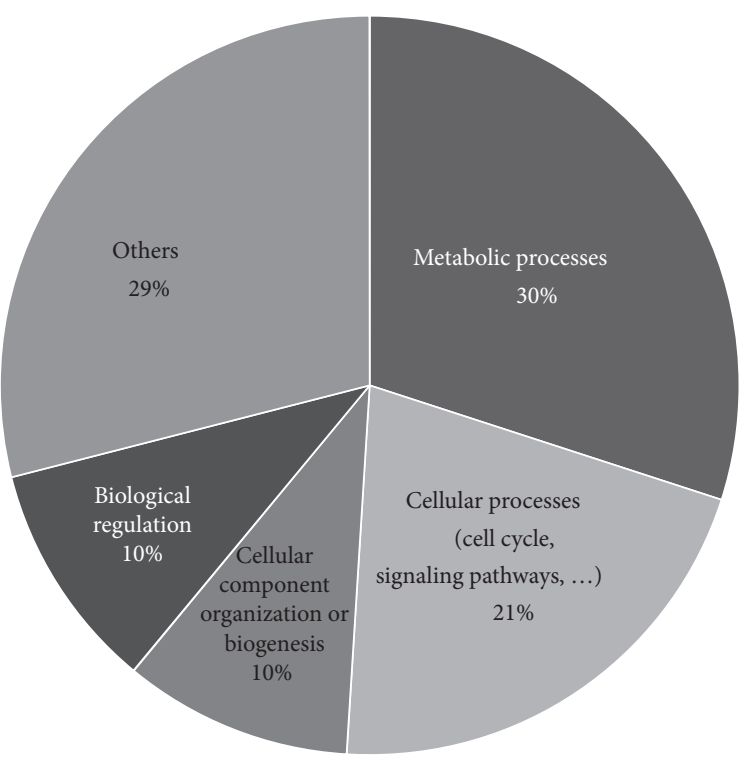

(a)

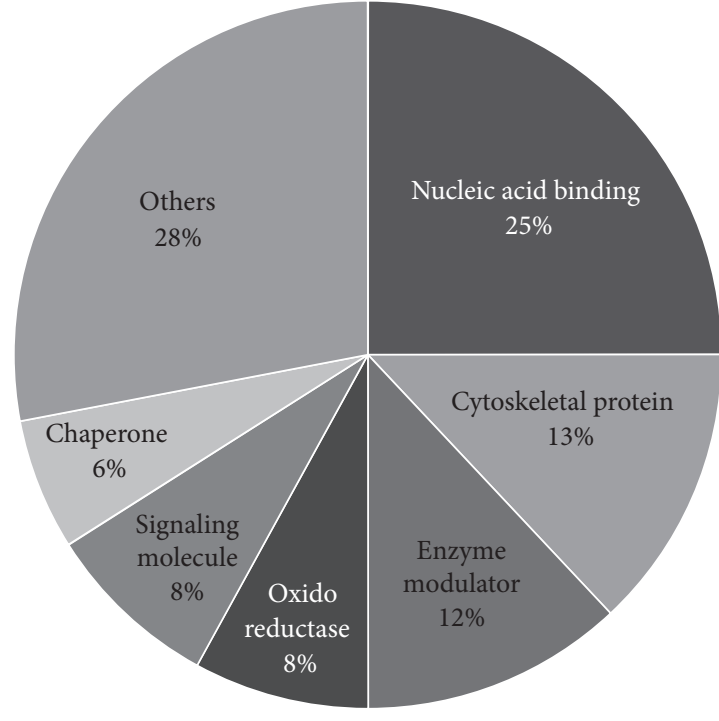

(b)

FIGURE 1: Functional distribution of the 58 proteins identified as dysregulated with aging according to biological processes (a) and PANTHER protein class (b) categories. Assignments were made with PANTHER tool. The numbers in brackets correspond to the percentage of identified proteins classified in the category. If a protein is classified into 2 ontology terms that are not parent or child to each other, it counts in the 2 classes.

nucleic acid-binding proteins $(25 \%)$, cytoskeletal proteins (13\%), and enzyme modulators (12\%). These proteins are mostly involved in metabolism (30\%) or cellular process (21\%) such as cell cycle and cell signaling pathways. Similar results have been observed in a previous transcriptomic study [7]. Pathway enrichment analysis reveals metal (zinc and copper) homeostasis as one of the most enriched pathways which is consistent with the observed dysregulation of several metallothionein proteins that bind diverse types of metal and also participated in oxidative stress response [26]. Oxidative stress and electron transport chain pathways are also in the enriched pathways' list, and this is consistent with the increase of reactive oxygen species (ROS) production with aging [3].

In this work, tubulin beta-3 chain expression is upregulated with aging in our proteomic experiment and also in western blot analyses on samples from several donors. Statistical analysis of these data has shown that tubulin beta-3 chain may discriminate age status. Tubulin beta- 3 chain is a component of the microtubules that are complex polymers composed of tandem repeats of $\alpha$ - and $\beta$-tubulin heterodimers. In humans, six $\beta$-tubulin isoforms have been described and the isoform composition of the microtubule is determining its behavior. For example, it has been shown that in vitro purified microtubules enriched in tubulin beta- 3 chain are more dynamic compared to microtubules containing other $\beta$-tubulin isoforms [27]. Tubulin beta-3 chain mutations have been linked in humans to different types of neurological disorders with abnormal axon guidance $[28,29]$. Tubulin beta-3 was also reported as a biomarker for melanocyte lineage and as involved in melanocyte differentiation and melanogenesis [30], and it has been shown that tubulin beta-3 expression is decreased in senescent melanocytes [31].
Locher et al. [30] also reported that tubulin beta-3 may play a substantial role in melanosome transport which is regulated by proteins (such as kinesin and dynein) using microtubule tracks. Moreover, melanosomes may be transferred from melanocytes to keratinocytes through the shedding vesicle system [32], but the cellular process is still unclear and no data was reported concerning ageing aspects. Interestingly, tubulin beta-3 was identified as a direct downstream protein of human melanocortin 1 receptor (MC1R) [33], a protein associated to skin pigmentation, ultraviolet radiation, and to other aspects such as skin cancers [34]. High level of tubulin beta-3 chain has been linked to resistance to antitubulin agents such as taxanes and vinorelbine and lower overall survival in nonsmall cell lung cancer (NSCLC) [35-37] and prostate tumor patients [38]. But the prognostic value of tubulin beta- 3 chain is still debated in cutaneous malignant melanoma prognosis [39]. The high expression of tubulin beta-3 chain in NSCLC has been shown to be regulated by ras, PI3/akt, and MAP kinase-ERK signaling [40]. Tubulin beta-3 chain has also been described to be a prognostic marker for bladder urothelial carcinoma with patients showing a higher level of tubulin beta- 3 chain presenting a shorter disease-free survival [41]. To date, no publication reported tubulin beta-3 chain protein as a candidate biomarker for aging and there is no known mechanism of tubulin beta-3 chain dysregulation in skin aging. But it is interesting to notice that alterations of the cytoskeleton have been reported with aging [7] and that mutations in lamin genes (type $\mathrm{V}$ intermediate filaments) are responsible for some premature aging diseases such as the Hutchinson-Gilford progeria syndrome (HGPS) [42].

In our study, we identified other dysregulated proteins such as peroxiredoxin 3,6-phosphofructokinase, platelet 
TABLE 4: List of top enriched pathways provided after overrepresentation analysis with PathVisio. Positive $(r)$ is the number of genes in the pathway meeting the criterion. Measured $(n)$ is the number of genes in the pathway measured in the experiment. Total is the total number of elements in the pathway. $Z$-score is the score calculated for overrepresentation analysis. Pathways with a high $Z$-score have more significantly up- or downregulated genes than expected.

\begin{tabular}{|c|c|c|c|c|c|c|}
\hline Pathway & Positive $(r)$ & Measured $(n)$ & Total & $\%$ & $Z$-score & $p$ value (permuted) \\
\hline Zinc homeostasis & 4 & 4 & 39 & $100.00 \%$ & 3.30 & 0.000 \\
\hline Copper homeostasis & 5 & 6 & 58 & $83.33 \%$ & 3.13 & 0.000 \\
\hline Arachidonate epoxygenase/epoxide hydrolase & 2 & 2 & 17 & $100.00 \%$ & 2.33 & 0.001 \\
\hline DNA replication & 2 & 2 & 50 & $100.00 \%$ & 2.33 & 0.009 \\
\hline Retinoblastoma (RB) in cancer & 2 & 2 & 98 & $100.00 \%$ & 2.33 & 0.012 \\
\hline Histone modifications & 11 & 25 & 69 & $44.00 \%$ & 1.98 & 0.027 \\
\hline Aryl hydrocarbon receptor & 1 & 1 & 51 & $100.00 \%$ & 1.65 & 0.048 \\
\hline Cardiac hypertrophic response & 1 & 1 & 60 & $100.00 \%$ & 1.65 & 0.063 \\
\hline Constitutive androstane receptor pathway & 1 & 1 & 34 & $100.00 \%$ & 1.65 & 0.029 \\
\hline Dual hijack model of Vif in HIV infection & 1 & 1 & 9 & $100.00 \%$ & 1.65 & 0.007 \\
\hline Endochondral ossification & 1 & 1 & 69 & $100.00 \%$ & 1.65 & 0.072 \\
\hline Endothelin pathways & 1 & 1 & 47 & $100.00 \%$ & 1.65 & 0.047 \\
\hline Gastric cancer network 1 & 1 & 1 & 32 & $100.00 \%$ & 1.65 & 0.027 \\
\hline Melatonin metabolism and effects & 1 & 1 & 55 & $100.00 \%$ & 1.65 & 0.057 \\
\hline NOTCH1 regulation of human endothelial cell calcification & 1 & 1 & 18 & $100.00 \%$ & 1.65 & 0.014 \\
\hline Notch signaling pathway & 1 & 1 & 62 & $100.00 \%$ & 1.65 & 0.058 \\
\hline RalA downstream regulated genes & 1 & 1 & 13 & $100.00 \%$ & 1.65 & 0.015 \\
\hline T-cell receptor and costimulatory signaling & 1 & 1 & 45 & $100.00 \%$ & 1.65 & 0.050 \\
\hline TarBasePathway & 1 & 1 & 19 & $100.00 \%$ & 1.65 & 0.019 \\
\hline Type II interferon signaling (IFNG) & 1 & 1 & 38 & $100.00 \%$ & 1.65 & 0.043 \\
\hline Metapathway biotransformation & 2 & 3 & 189 & $66.67 \%$ & 1.55 & 0.120 \\
\hline Cytoplasmic ribosomal proteins & 13 & 34 & 89 & $38.24 \%$ & 1.54 & 0.121 \\
\hline Circadian rythm-related genes & 5 & 11 & 210 & $45.45 \%$ & 1.40 & 0.146 \\
\hline Apoptosis modulation and signaling & 3 & 6 & 97 & $50.00 \%$ & 1.28 & 0.190 \\
\hline Alzheimers disease & 4 & 9 & 163 & $44.44 \%$ & 1.19 & 0.259 \\
\hline Electron transport chain & 4 & 9 & 118 & $44.44 \%$ & 1.19 & 0.252 \\
\hline Oxidative stress & 2 & 4 & 32 & $50.00 \%$ & 1.04 & 0.232 \\
\hline Preimplantation embryo & 2 & 4 & 60 & $50.00 \%$ & 1.04 & 0.299 \\
\hline Vitamin B12 metabolism & 2 & 4 & 118 & $50.00 \%$ & 1.04 & 0.337 \\
\hline TNF alpha signaling pathway & 3 & 7 & 97 & $42.86 \%$ & 0.95 & 0.340 \\
\hline
\end{tabular}

type, and cornifin-B. Thioredoxin-dependent peroxide reductase, mitochondrial, also known as peroxiredoxin 3 (PrxIII), a mitochondrial member of the antioxidant family of thioredoxin (Trx) peroxidases, was found upregulated with aging in our study. Two other family members, peroxiredoxins 1 and 2, were also upregulated in a previous report [14]. Peroxiredoxins are important cellular antioxidant; indeed, they act as hydrogen peroxide and organic hydroperoxide scavengers [43]. It is well established that with age, there is an increase in reactive oxygen species (ROS) production and a decrease in antioxidant activity both contributing to chronological aging [3]. In oxidative stress conditions, PrxIII undergoes overoxidation and subsequent irreversible inactivation. And it has been shown that in rats, this modified PrxIII form accumulates with aging [44]. In our analysis, we did not identify the peptide containing the cysteine that is overoxidized to sulfonic acid and we then cannot discriminate between the two forms, explaining why, in consequence, we observed a global upregulation of the protein. Concerning 6-phosphofructokinase, platelet type (ATP-PFK) which is upregulated with aging in our study, this enzyme catalyzes the phosphorylation of D-fructose 6-phosphate to fructose 1,6-bisphosphate by ATP, the first committing step of glycolysis. It has been shown that human primary keratinocytes derived from elderly donors showed higher glucose uptake and increased lactate production, which are the indicators of a shift in metabolism towards increased glycolysis [45]. Thus, the observed upregulation of ATP-PFK is correlated with the increased glycolysis in primary keratinocytes. Interestingly, cornifin-B is a marker of keratinocyte differentiation [46] and two transcriptomic studies reported that cornifin-B was downregulated with aging using women epidermis [9] and skin biopsies [47]. Our study is in concordance with this view as our proteomic 


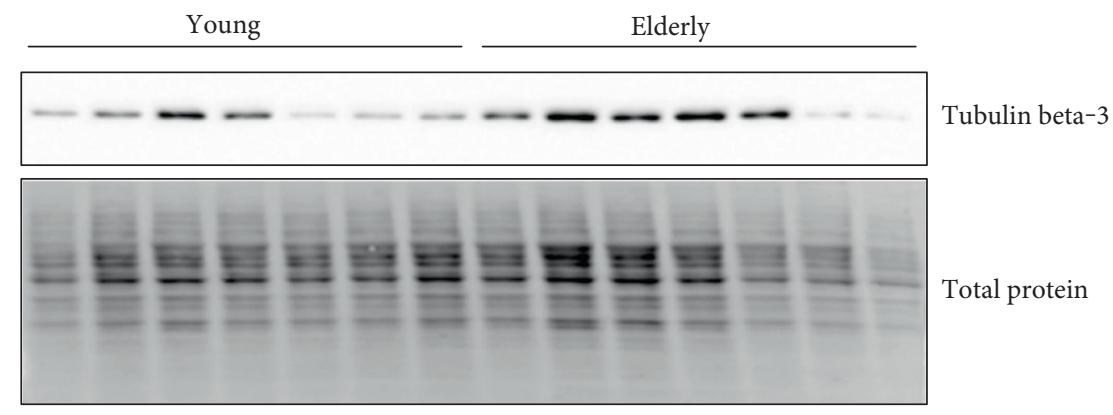

(a)

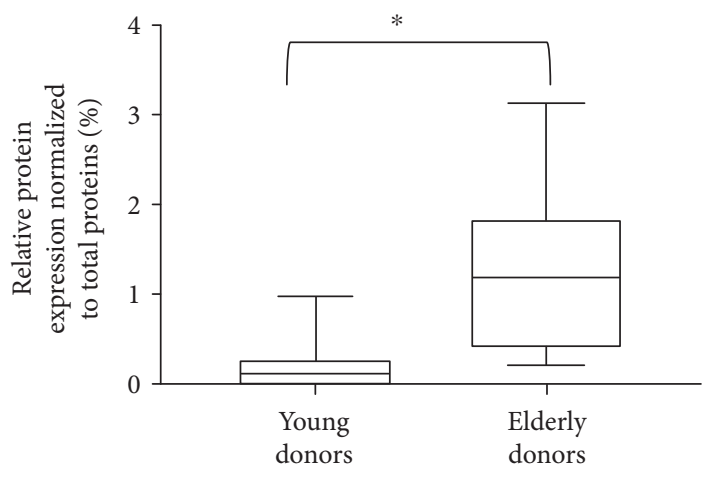

(b)

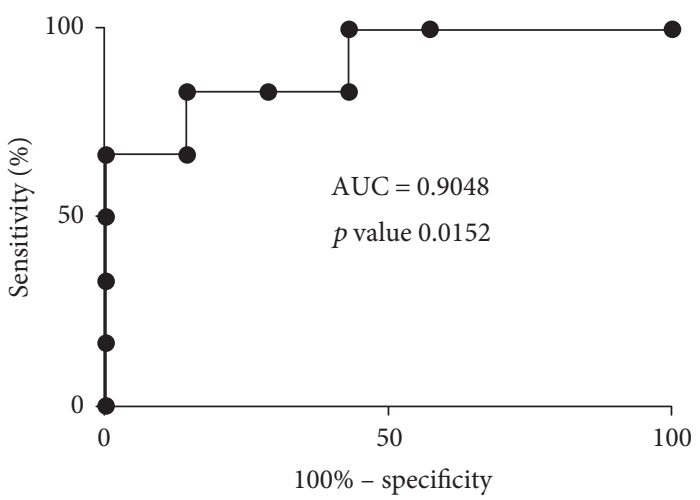

(c)

Figure 2: (a) Western blot analysis of protein extract from young and elderly keratinocytes with tubulin beta-3 chain. (b) Box plots of relative protein expression of tubulin beta-3 chain in young and elderly donors (based on western blot data by considering the relative intensity of the specific antibodies on the membrane versus the amount of protein loaded on the gel for young and elderly donors, *significant $p$ value $<0.05$ ( $p$ value 0.0152$)$ ). (c) Receiver operating characteristic curve (ROC curve) with an AUC of 0.9048 .

study showed a downregulation of cornifin-B expression with aging (iTRAQ ratio erlderly versus young of 0.405 with a $p$ value ratio of $2.54 \times 10^{-2}$ and a $p$ value sample of $\left.3.18 \times 10^{-6}\right)$.

Comparing our results with other studies aimed at identifying biomarkers of skin aging shows some differences that may be explained by different type/origin of skin samples, gender, difference in sample processing all along the workflow, and the variable correlation between mRNA and protein expression levels [48]. But using different and complementary approaches is interesting as it can lead to the identification of even more candidate biomarkers than with a single method. Also, considering the occurrence of oxidative stress during aging and the subsequent induced altered posttranslational modifications (PTMs) of proteins such as carbonylation, 3-nitrityrosilation, emphasis must be placed on the study of PTMs with aging in future proteomic experiment concerning skin aging [49].

\section{Conclusions}

Defining the differential protein signature with aging even if these changes could be initiating adaptive or compensatory events is crucial to further increase our knowledge of skin aging. Our aim was to identify some biomarker candidates for skin aging from human primary keratinocyte culture. 58 proteins were dysregulated with aging, and from this, tubulin beta- 3 chain was also observed dysregulated in western blot analysis of keratinocyte extracts isolated from multiple donors. Statistical analysis has confirmed especially that an increase in tubulin beta-3 chain is associated with aging. Further studies will be needed in order to evaluate the effect of this change of expression on the complex process of aging.

This study brings a new effort to reach a better understanding of the biology of skin aging and to identify new and specific targets that could help to diagnose, prevent, and treat skin aging. Indeed, emerging diagnostic tools now require a combination of multiple biomarkers to achieve a better accuracy, and we propose that tubulin beta- 3 chain could be one of these.

\section{Conflicts of Interest}

The authors declare that there is no conflict of interest regarding the publication of this paper.

\section{Acknowledgments}

The authors would like to thank Valérie Cunin, Sylvie Michelland, and David Beal for providing their help and technical assistance and Friederike Ehrhart for the help with PathVisio. 


\section{References}

[1] K. Christensen, G. Doblhammer, R. Rau, and J. W. Vaupel, "Ageing populations: the challenges ahead," Lancet, vol. 374, no. 9696, pp. 1196-1208, 2009.

[2] C. C. Zouboulis and E. Makrantonaki, "Clinical aspects and molecular diagnostics of skin aging," Clinics in Dermatology, vol. 29, no. 1, pp. 3-14, 2011.

[3] B. Poljšak, R. G. Dahmane, and A. Godić, "Intrinsic skin aging: the role of oxidative stress," Acta Dermatovenerologica Alpina, Panonica, et Adriatica, vol. 21, no. 2, pp. 33-36, 2012.

[4] E. Makrantonaki, C. C. Zouboulis, and J. William, "Cunliffe Scientific Awards. Characteristics and pathomechanisms of endogenously aged skin," Dermatology (Basel, Switzerland), vol. 214, no. 4, pp. 352-360, 2007.

[5] J. M. Zahn, S. Poosala, A. B. Owen et al., "AGEMAP: a gene expression database for aging in mice," PLoS Genetics, vol. 3, no. 11, Article ID e201, 2007.

[6] J. M. Zahn and S. K. Kim, "Systems biology of aging in four species," Current Opinion in Biotechnology, vol. 18, no. 4, pp. 355-359, 2007.

[7] T. Lener, P. R. Moll, M. Rinnerthaler, J. Bauer, F. Aberger, and K. Richter, "Expression profiling of aging in the human skin," Experimental Gerontology, vol. 41, no. 4, pp. 387-397, 2006.

[8] E. Makrantonaki, T. C. Brink, V. Zampeli et al., "Identification of biomarkers of human skin ageing in both genders. Wnt signalling - a label of skin ageing?” PloS One, vol. 7, no. 11, Article ID e50393, 2012.

[9] G. Raddatz, S. Hagemann, D. Aran et al., "Aging is associated with highly defined epigenetic changes in the human epidermis," Epigenetics \& Chromatin, vol. 6, no. 1, p. 36, 2013.

[10] M. Bantscheff, M. Schirle, G. Sweetman, J. Rick, and B. Kuster, "Quantitative mass spectrometry in proteomics: a critical review," Analytical and Bioanalytical Chemistry, vol. 389, no. 4, pp. 1017-1031, 2007.

[11] M. Latterich, M. Abramovitz, and B. Leyland-Jones, "Proteomics: new technologies and clinical applications," European Journal of Cancer, vol. 44, no. 18, pp. 2737-2741, 2008.

[12] T. C. Walther and M. Mann, "Mass spectrometry-based proteomics in cell biology," The Journal of Cell Biology, vol. 190, no. 4, pp. 491-500, 2010.

[13] V. C. Wasinger, M. Zeng, and Y. Yau, "Current status and advances in quantitative proteomic mass spectrometry," International Journal of Proteomics, vol. 2013, no. 2, pp. 1-12, 2013.

[14] M. Laimer, T. Kocher, A. Chiocchetti et al., "Proteomic profiling reveals a catalogue of new candidate proteins for human skin aging," Experimental Dermatology, vol. 19, no. 10, pp. 912-918, 2010.

[15] C. Delattre, E. Winstall, C. Lessard et al., "Proteomic analysis identifies new biomarkers for postmenopausal and dry skin," Experimental Dermatology, vol. 21, no. 3, pp. 205-210, 2012.

[16] P. Gromov, G. L. Skovgaard, H. Palsdottir, I. Gromova, M. Østergaard, and J. E. Celis, "Protein profiling of the human epidermis from the elderly reveals up-regulation of a signature of interferon-gamma-induced polypeptides that includes manganese-superoxide dismutase and the p85beta subunit of phosphatidylinositol 3-kinase," Molecular \& Cellular Proteomics: MCP, vol. 2, no. 2, pp. 70-84, 2003.

[17] S. Seidenari, A. Pagnoni, A. Di Nardo, and A. Giannetti, "Echographic evaluation with image analysis of normal skin: variations according to age and sex," Skin Pharmacology, vol. 7, no. 4, pp. 201-209, 1994.

[18] N. J. Raine-Fenning, M. P. Brincat, and Y. Muscat-Baron, "Skin aging and menopause: implications for treatment," American Journal of Clinical Dermatology, vol. 4, no. 6, pp. 371-378, 2003.

[19] V. Ringa, N. Varnoux, S. Piault, and G. Bréart, "Hormone therapy use among postmenopausal French women before the publication of the Women's Health Initiative study: duration of use and factors associated with discontinuation," Fertility and Sterility, vol. 83, no. 6, pp. 1771-1779, 2005.

[20] S. Mouret, C. Baudouin, M. Charveron, A. Favier, J. Cadet, and T. Douki, "Cyclobutane pyrimidine dimers are predominant DNA lesions in whole human skin exposed to UVA radiation," Proceedings of the National Academy of Sciences of the United States of America, vol. 103, no. 37, pp. 13765-13770, 2006.

[21] F. P. Breitwieser, A. Müller, L. Dayon et al., "General statistical modeling of data from protein relative expression isobaric tags," Journal of Proteome Research, vol. 10, no. 6, pp. 27582766, 2011.

[22] H. Mi, A. Muruganujan, and P. D. Thomas, "PANTHER in 2013: modeling the evolution of gene function, and other gene attributes, in the context of phylogenetic trees," Nucleic Acids Research, vol. 41, no. Database issue, pp. D377-D386, 2013.

[23] M. Kutmon, M. P. van Iersel, A. Bohler et al., "PathVisio 3: an extendable pathway analysis toolbox," PLoS Computational Biology, vol. 11, no. 2, Article ID e1004085, 2015.

[24] A. Martín-Bernabé, R. Cortés, S. G. Lehmann, M. Seve, M. Cascante, and S. Bourgoin-Voillard, "Quantitative proteomic approach to understand metabolic adaptation in non-small cell lung cancer," Journal of Proteome Research, vol. 13, no. 11, pp. 4695-4704, 2014.

[25] C. Collin, R. Moll, S. Kubicka, J. P. Ouhayoun, and W. W. Franke, "Characterization of human cytokeratin 2, an epidermal cytoskeletal protein synthesized late during differentiation," Experimental Cell Research, vol. 202, no. 1, pp. 132-141, 1992.

[26] G. K. Andrews, "Regulation of metallothionein gene expression by oxidative stress and metal ions," Biochemical Pharmacology, vol. 59, no. 1, pp. 95-104, 2000.

[27] D. Panda, H. P. Miller, A. Banerjee, R. F. Ludueña, and L. Wilson, "Microtubule dynamics in vitro are regulated by the tubulin isotype composition," Proceedings of the National Academy of Sciences of the United States of America, vol. 91, no. 24, pp. 11358-11362, 1994.

[28] M. A. Tischfield, H. N. Baris, C. Wu et al., "Human TUBB3 mutations perturb microtubule dynamics, kinesin interactions, and axon guidance," Cell, vol. 140, no. 1, pp. 74-87, 2010.

[29] M. A. Tischfield, G. Y. Cederquist, M. L. Gupta, and E. C. Engle, "Phenotypic spectrum of the tubulin-related disorders and functional implications of disease-causing mutations," Current Opinion in Genetics \& Development, vol. 21, no. 3, pp. 286-294, 2011.

[30] H. Locher, K. E. de Rooij, J. C. M. J. de Groot et al., "Class III $\beta$-tubulin, a novel biomarker in the human melanocyte lineage," Differentiation, vol. 85, no. 4-5, pp. 173-181, 2013.

[31] K. Orfanidis, P. Wäster, K. Lundmark, I. Rosdahl, and K. Öllinger, "Evaluation of tubulin $\beta-3$ as a novel senescenceassociated gene in melanocytic malignant transformation," Pigment Cell \& Melanoma Research, vol. 30, no. 2, pp. 243254, 2017. 
[32] H. Ando, Y. Niki, M. Ito et al., "Melanosomes are transferred from melanocytes to keratinocytes through the processes of packaging, release, uptake, and dispersion," The Journal of Investigative Dermatology, vol. 132, no. 4, pp. 1222-1229, 2012.

[33] M. Dalziel, M. Kolesnichenko, R. P. das Neves, F. Iborra, C. Goding, and A. Furger, "Alpha-MSH regulates intergenic splicing of MC1R and TUBB3 in human melanocytes," Nucleic Acids Research, vol. 39, no. 6, pp. 2378-2392, 2011.

[34] F. Rouzaud, A. L. Kadekaro, Z. A. Abdel-Malek, and V. J. Hearing, "MC1R and the response of melanocytes to ultraviolet radiation," Mutation Research, vol. 571, no. 1-2, pp. 133152, 2005.

[35] P. Sève, J. Mackey, S. Isaac et al., "Class III beta-tubulin expression in tumor cells predicts response and outcome in patients with non-small cell lung cancer receiving paclitaxel," Molecular Cancer Therapeutics, vol. 4, no. 12, pp. 2001-2007, 2005.

[36] P. Sève, S. Isaac, O. Trédan et al., "Expression of class III \{beta\}-tubulin is predictive of patient outcome in patients with non-small cell lung cancer receiving vinorelbine-based chemotherapy," Clinical Cancer Research, vol. 11, no. 15, pp. 5481-5486, 2005.

[37] P. Sève and C. Dumontet, "Is class III $\beta$-tubulin a predictive factor in patients receiving tubulin-binding agents?" The Lancet Oncology, vol. 9, no. 2, pp. 168-175, 2008.

[38] G. Ploussard, S. Terry, P. Maillé et al., "Class III beta-tubulin expression predicts prostate tumor aggressiveness and patient response to docetaxel-based chemotherapy," Cancer Research, vol. 70, no. 22, pp. 9253-9264, 2010.

[39] A. Shimizu, K. Kaira, M. Yasuda, T. Asao, and O. Ishikawa, "Decreased expression of class III $\beta$-tubulin is associated with unfavourable prognosis in patients with malignant melanoma," Melanoma Research, vol. 26, no. 1, pp. 29-34, 2016.

[40] G. Levallet, E. Bergot, M. Antoine et al., "High TUBB3 expression, an independent prognostic marker in patients with early non-small cell lung cancer treated by preoperative chemotherapy, is regulated by K-Ras signaling pathway," Molecular Cancer Therapeutics, vol. 11, no. 5, pp. 1203-1213, 2012.

[41] F. Massari, E. Bria, C. Ciccarese et al., "Prognostic value of beta-tubulin-3 and c-Myc in muscle invasive urothelial carcinoma of the bladder," PloS One, vol. 10, no. 6, Article ID e0127908, 2015.

[42] S. Gonzalo, R. Kreienkamp, and P. Askjaer, "HutchinsonGilford progeria syndrome: a premature aging disease caused by LMNA gene mutations," Ageing Research Reviews, vol. 33, pp. 18-29, 2017.

[43] T. Nyström, J. Yang, and M. Molin, "Peroxiredoxins, gerontogenes linking aging to genome instability and cancer," Genes \& Development, vol. 26, no. 18, pp. 2001-2008, 2012.

[44] C. Musicco, V. Capelli, V. Pesce et al., "Accumulation of overoxidized peroxiredoxin III in aged rat liver mitochondria," Biochimica et Biophysica Acta, vol. 1787, no. 7, pp. 890-896, 2009.

[45] S. Prahl, T. Kueper, T. Biernoth et al., "Aging skin is functionally anaerobic: importance of coenzyme Q10 for anti aging skin care," BioFactors (Oxford, England), vol. 32, no. 1-4, pp. 245-255, 2008.

[46] J. Tesfaigzi and D. M. Carlson, "Expression, regulation, and function of the SPR family of proteins. A review," Cell Biochemistry and Biophysics, vol. 30, no. 2, pp. 243-265, 1999.
[47] J. A. McGrath, M. K. Robinson, and R. L. Binder, "Skin differences based on age and chronicity of ultraviolet exposure: results from a gene expression profiling study," The British Journal of Dermatology, vol. 166, Supplement 2, pp. 9-15, 2012.

[48] B. Schwanhäusser, D. Busse, N. Li et al., "Global quantification of mammalian gene expression control," Nature, vol. 473, no. 7347, pp. 337-342, 2011.

[49] D. Ortuño-Sahagún, M. Pallàs, and A. E. Rojas-Mayorquín, "Oxidative stress in aging: advances in proteomic approaches," Oxidative Medicine and Cellular Longevity, vol. 2014, Article ID 573208, p. 18, 2014. 


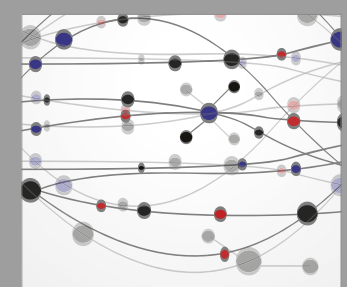

The Scientific World Journal
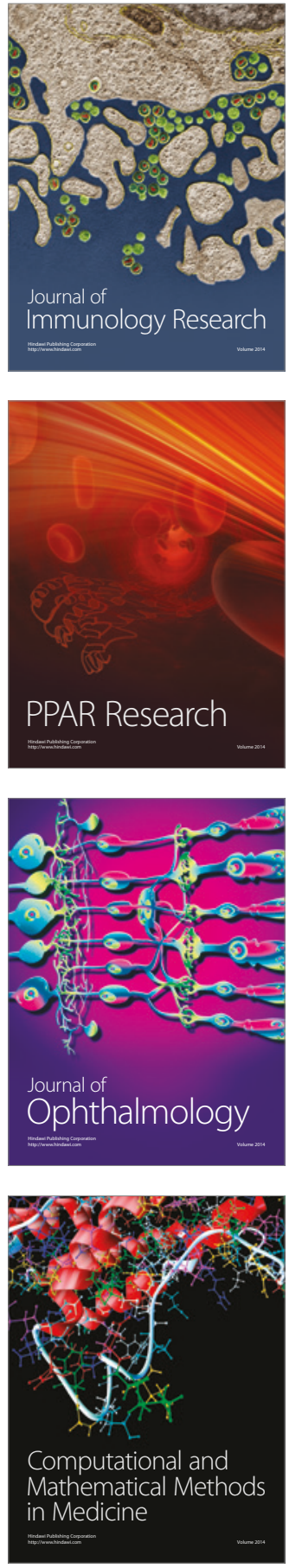

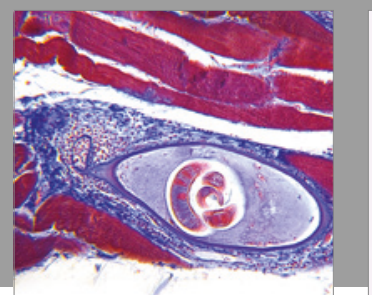

Gastroenterology Research and Practice
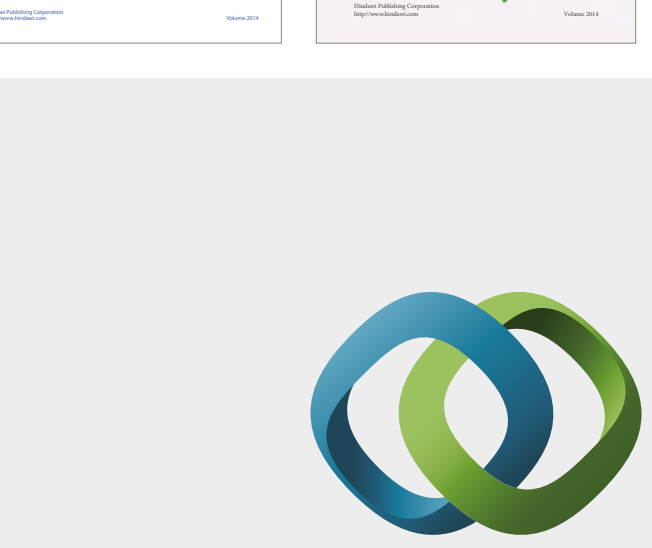

\section{Hindawi}

Submit your manuscripts at

https://www.hindawi.com
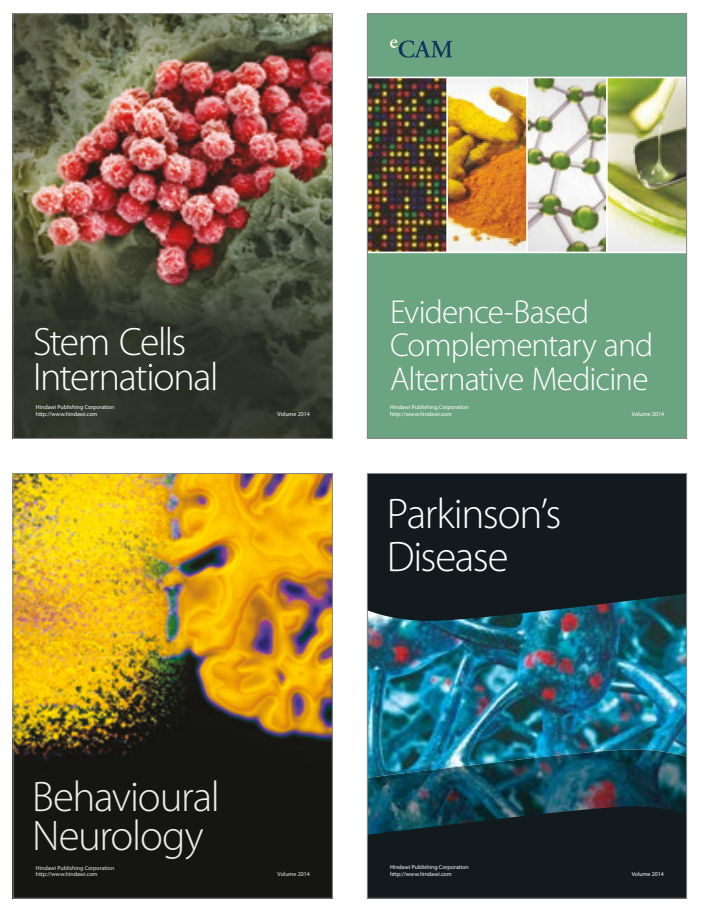
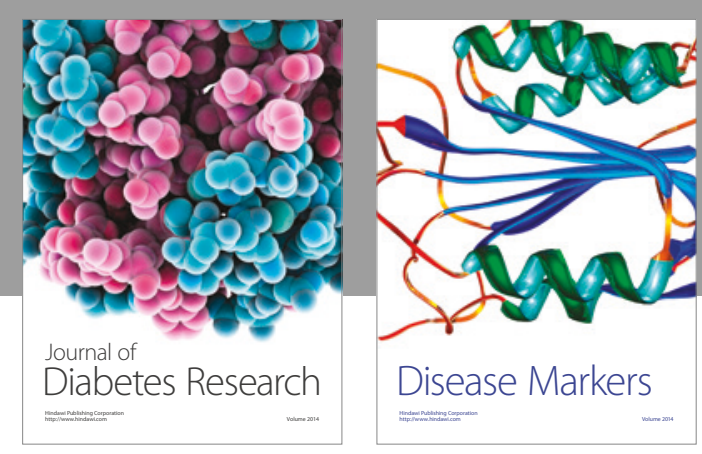

Disease Markers
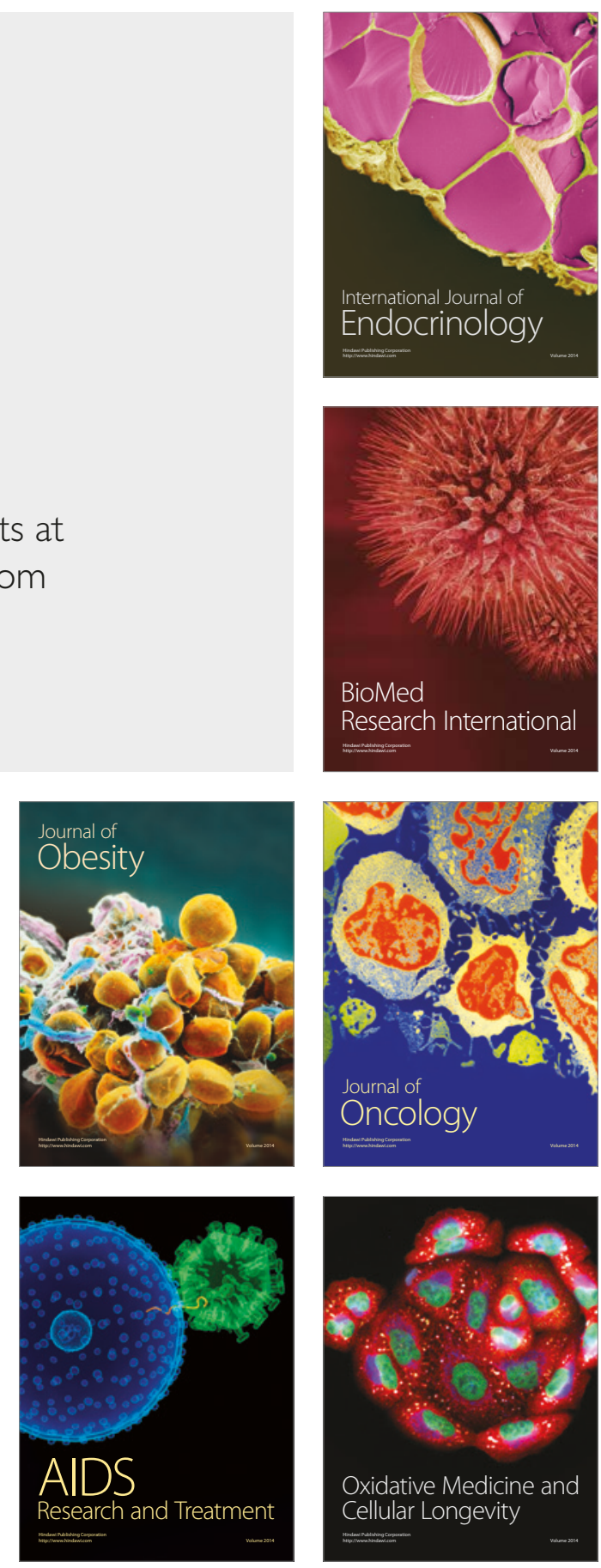